\title{
12
}

\section{Chemical Hazards}

Chemicals are ubiquitous. They are used in virtually all occupations, and everyone will encounter chemicals of one type or another in his or her lifetime (Table 12.1). Many chemicals can be hazardous, especially if used improperly. Laboratory research in the biomedical laboratory deals with a wide variety of chemicals. Flammable and toxic chemicals are hazards most frequently encountered in the laboratory: a recent survey reported that 82 percent of biologists work with toxic chemicals (241). Unlike the chemist, however, the biomedical researcher usually does not work with chemicals specifically to study chemical phenomena, such as chemical interactions or molecular structure, or to develop techniques,

TABLE 12.1 Common chemicals

\begin{tabular}{ll}
\hline Ammonia & Isopropyl (rubbing) \\
Benzine & alcohol \\
Bleach & Kerosene \\
Brass polish & Lawn fertilizer \\
Brush cleaner & Mimeograph ink \\
Copier toner & Motor oil \\
Detergents & Natural gas \\
Drain cleaner (lye) & Paint and thinner \\
Epoxy adhesive & Pharmaceuticals \\
Floor polish and stripper & Propane \\
Furniture polish & Rubber and contact \\
Gasoline & cement \\
Glass cleaner & Turpentine \\
Herbicide & Toilet bowl cleaner \\
Hydrogen peroxide & Typing correction fluid \\
Insecticide & and thinner \\
& Vinegar \\
\hline
\end{tabular}

such as chemical synthesis. For biomedical researchers, chemicals are just some of the tools used in analytical techniques and as reagents in metabolic studies. Toxicologists, on the other hand, study chemicals to learn about their toxic effects and mechanisms, and therefore these researchers are aware of the hazards of such compounds. However, the wide diversity of chemicals used in biomedical research may prompt researchers to downplay the potential hazard of many chemicals, thus leading to less cautious handling of these substances than warranted. Also, careless handling of chemicals may occur in many laboratories simply because many highly hazardous chemicals are so common and familiar to laboratory workers. Household experience with chemicals also contributes to this lack of awareness of chemical hazards. Most people become aware of the common household hazards of electricity, fire, and hot objects as children, but few learn more than the elementary precautions to be taken when handling household chemicals.

Chemicals can be classified in many ways. A list of the most common ways to classify them follows:

- Molecular composition. Elements or compounds; organic or inorganic chemicals.

- Physical state. Solids, liquids, or gases.

- Isotopic composition. Nonradioactive, radioactive, or rare stable isotopes.

- Chemical action. Oxidizing agents or reducing agents. 
- Chemical group. Acidic, basic, or nonionic substances.

- Chemical structure. Aromatic or aliphatic compounds; alcohols, ketones, esters, ethers, etc.

For the purpose of discussing chemical hazards, chemicals may be grouped into general categories which reflect their hazardous action on materials or personal health and safety. These hazard groups are composed of chemicals from all of the above chemical classes and physical states. For example, one would not consider lead in the solid form to be particularly hazardous (unless a block of it were dropped on one's toes), but lead dust, also a solid form of the substance, is a very hazardous substance. We will see that an examination only of the substance's chemical composition, physical state, or other general characteristics in themselves seldom provides clues to the chemical's potential hazard. The general hazard categories into which chemicals are commonly grouped are listed here. This classification system will be used in the remainder of this chapter.

- Corrosives. A wide range of chemicals including acids and anhydrides, alkalis, halogens, organic halides, dehydrating agents, and oxidizing agents (Section 12.3).

- Toxic substances. Includes poisons, irritants, and asphyxiants (Section 12.4).

- Sensitizers. Produces a direct cytotoxic effect resulting in a skin irritation or sensitizes to elicit an allergic response (Section 12.5).

- Carcinogens. This is a special category of toxic substances that is generally considered separately (Section 12.6).

- Mutagens and teratogens. These are discussed in Section 12.7.

- Flammables. These chemicals may also be toxic and/or carcinogenic but primarily pose fire risks (Section 12.8).

- Explosives. This is a special category of combustible chemicals that are considered to be particularly hazardous because they can explode (Section 12.9). Some explosives can also burn slowly without exploding; thus these substances may not be considered fire hazards, but obviously still require precautions in handling.

The particular hazards of each of these chemical groups and the precautions that should be used in handling these substances will be discussed in detail in this chapter.

\subsection{Risk Assessment of Chemical Hazards}

We discussed the basic principles of risk assessment in the Introduction to this work and of biological hazards in Section 11.2. The assessment of the risks of chemical hazards poses similar factors and concerns as the risk assessment of biological hazards, and some that are unique, but many of these factors are usually more predictable than those encountered in research with hazardous biological agents. There are two reasons for this. First, chemical reactions are governed by physical laws-those of thermodynamics, mass action, and reaction kinetics. Although the risks of adverse health effects in personnel caused by chemical exposures can be unpredictable because of uncertainties in assessing routes of exposure, threshold doses, and toxic effects, many of the hazards caused by chemical reactions can be predicted by careful analysis of the reactants and the reaction conditions. These predictions can include intermediate and final products, amount of heat liberated, stability of the reaction mixture, and other factors. Second, the gross effects on health and property can be controlled by carefully isolating the material or reaction, handling with suitable protection, and using quantities which can be safely controlled. These factors are in contrast with those observed in the handling of, for example, infectious agents, where control of many of these factors cannot be as readily assured.

The risk assessment of chemical hazards requires the analysis of many factors. However, the most important rule for minimizing risk is to exercise common sense in the design of the experiment involving the use of the chemical. The following are some of the important 
factors to be considered when working with hazardous chemicals:

- Properties. Analyze the physical, chemical, and biological properties of the material and the effect of each on both worker and material safety. Examples: chemical composition, ionic form, $\mathrm{pH}$, stability, storage conditions, particle size, and presence of contaminants or impurities.

- Effects. Determine the biological and physical effects and hazards, including routes of exposure, latency times, and dose and threshold effects, if any. Prior experience with the substance, its analogs and derivatives, is very important. Examples: solubility in biological fluids, metabolic and target organ effects.

- Use. Determine how the substance is to be used in the operation, the quantity used, and how the substance is confined in reaction containers. Plan the procedures to minimize the risks of handling the substance.

- Exposure. Evaluate the length of time the substance is in use to determine potential personal exposure. Also consider the number of people having access to the substance or who work in the area where the substance is in use.

- Purity. Determine the purity of the reactants, considering the presence of impurities which may act as catalysts; also, consider the possibility that solvents or diluents may affect formation of reaction intermediates.

- Protective equipment. Assess the need for the use of personal protective equipment, its availability and adequacy (Chapter 2), and the requirement for adequate ventilation including the need for the use of fume hoods.

- Alternative processes. Consider the possibility that a less hazardous substance could be substituted in the process.

- Evaluation of the experiment. Determine the hazards associated with the experiment and the types of emergency situations that might arise, and what facilities are available to deal with these potential situations.

- Control of experimental conditions. Determine the most effective means of controlling the reaction. Consider the necessity of con- trolling reaction temperature to avoid, for example, exothermic decomposition of reaction mixtures which can lead to an explosion. The rate of reaction increases exponentially with temperature increase, and in many cases an increase of $10^{\circ} \mathrm{C}$ will cause the reaction rate to approximately double. Also consider the consequences of development of increased pressures in closed reaction systems, and methods to control rate of reactant addition. Rapid addition of reactants can cause runaway reactions, with all attendant hazards.

- Waste products. Determine the proper procedures for dealing with the disposal of hazardous reaction waste products, derivatives and reaction intermediates, and unused reactants.

- Personal practices. Consuming or storage of food or beverages in areas used to handle chemicals poses the usual hazard of the risk of ingestion of a toxic material. Smoking, or even carrying smoking materials, may also pose this hazard plus an unusual one: a respiratory ailment called "polymer-fume fever." This disease has resulted from fluorocarbons becoming absorbed on cigarettes, which, when smoked, resulted in the products of pyrolysis of the fluorocarbons being inhaled along with the smoke. The contamination came from the workplace air where the chemicals were present but at concentrations that were below the occupational threshold, and from handling cigarettes with contaminated fingers (340, p.403; 409).

- Working conditions. Have suitable spill control materials and contingency plans available for dealing with accidents. Be certain that hazardous materials are properly stored and that incompatible chemicals are not stored together (Table 12.2). Avoid working alone to reduce the chance of serious injury as a result of a single individual being overcome with toxic fumes should an accident occur.

- Warning properties. Consider, for example, whether the chemical has an odor or would cause pain upon contact of the substance with the skin. These factors can serve to warn 
TABLE 12.2 Examples of incompatible chemicals

Chemical

Acetic acid

Acetylene

Acetone

Alkali and alkaline earth metals (such as powdered aluminum or magnesium, calcium, lithium, sodium, potassium) Ammonia (anhydrous)

Ammonium nitrate

Aniline

Arsenical materials

Azides

Bromine

Calcium oxide

Carbon (activated)

Carbon tetrachloride

Chlorates

Chromic acid and chromium trioxide

Chlorine

Chlorine dioxide

Copper

Cumene hydroperoxide

Cyanides

Flammable liquids

Fluorine

Hydrocarbons (such as butane, propane, benzene)

Hydrocyanic acid

Hydrofluoric acid (anhydrous)

Hydrogen peroxide

Hydrogen sulfide

Hypochlorites

Iodine

Mercury

Nitrates

Nitric acid (concentrated)

Nitrites

Nitroparaffins

Oxalic acid

Oxygen

Perchloric acid

Peroxide, organic

Phosphorus (white)

Potassium

Potassium chlorate

Potassium perchlorate (see also chlorates)
Is incompatible and should not be mixed or stored with

Chromic acid, nitric acid, hydroxyl compounds, ethylene glycol, perchloric acid, peroxides, permanganates

Chlorine, bromine, copper, fluorine, silver, mercury

Concentrated nitric and sulfuric acid mixtures

Water, carbon tetrachloride or other chlorinated hydrocarbons, carbon dioxide, halogens

Mercury (in manometers, for example), chlorine, calcium hypochlorite, iodine, bromine, hydrofluoric acid (anhydrous)

Acids, powdered metals, flammable liquids, chlorates, nitrates, sulfur, finely divided organic or combustible materials

Nitric acid, hydrogen peroxide

Any reducing agent

Acids

See Chlorine

Water

Calcium hypochlorite, all oxidizing agents

Sodium

Ammonium salts, acids, powdered metals, sulfur, finely divided organic or combustible materials

Acetic acid, naphthalene, camphor, glycerol, alcohol, flammable liquids in general

Ammonia, acetylene, butadiene, butane, methane, propane (or other petroleum gases), hydrogen, sodium carbide, benzene, finely divided metals, turpentine

Ammonia, methane, phosphine, hydrogen sulfide

Acetylene, hydrogen peroxide

Acids (organic or inorganic)

Acids

Ammonium nitrate, chromic acid, hydrogen peroxide, nitric acid, sodium peroxide, halogens

Everything

Fluorine, chlorine, bromine, chromic acid, sodium peroxide

Nitric acid, alkali

Ammonia (aqueous or anhydrous)

Copper, chromium, iron, most metals or their salts, alcohols, acetone, organic materials, aniline, nitromethane, combustible materials

Fuming nitric acid, oxidizing gases

Acids, activated carbon

Acetylene, ammonia (aqueous or anhydrous), hydrogen

Acetylene, fulminic acid, ammonia

Sulfuric acid

Acetic acid, aniline, chromic acid, hydrocyanic acid, hydrogen sulfide, flammable liquids, flammable gases, copper, brass, any heavy metals

Acids

Inorganic bases, amines

Silver, mercury

Oils, grease, hydrogen, flammable liquids, solids, or gases

Acetic anhydride, bismuth and its alloys, alcohol, paper, wood, grease, oils

Acids (organic or mineral), avoid friction, store cold

Air, oxygen, alkalis, reducing agents

Carbon tetrachloride, carbon dioxide, water

Sulfuric and other acids

Sulfuric and other acids 
TABLE 12.2 Continued

\begin{tabular}{ll}
\hline Chemical & Is incompatible and should not be mixed or stored with \\
\hline Potassium permanganate & Glycerol, ethylene glycol, benzaldehyde, sulfuric acid \\
Selenides & Reducing agents \\
Silver & Acetylene, oxalic acid, tartartic acid, ammonium compounds, fulminic acid \\
Sodium & Carbon tetrachloride, carbon dioxide, water \\
Sodium nitrate & Ammonium nitrate and other ammonium salts \\
Sodium peroxide & Ethyl or methyl alcohol, glacial acetic acid, acetic anhydride, benzaldehyde, \\
& carbon disulfide, glycerin, ethylene glycol, ethyl acetate, methyl acetate, \\
Sulfides & furfural \\
Sulfuric acid & Acids \\
Tellurides & Potassium chlorate, potassium perchlorate, potassium permanganate (similar \\
& compounds of light metals, such as sodium, lithium) \\
\hline
\end{tabular}

From (317).

personnel of a problem. The $\mathrm{pH}$ of a substance is also a warning property.

- Advice. Consult with those who could give advice in reducing the hazards of an experiment and with those who could give emergency assistance if necessary.

One of the considerations in determination of risk mentioned above is the quantity of hazardous chemicals used in a process. Exposure potentials range from large users, almost always found in manufacturing or pilot plants where large quantities of the same compounds are handled day after day, to the small users, generally found in research laboratories where workers are more familiar than the factory worker with the substances used and their hazards, and who do not work with the same quantities of chemicals for extended periods, thus limiting their occupational exposure. Remember, though, that research laboratories may also be involved with work on new compounds which may pose unknown hazards. Another type of chemical exposure can be found in instructional laboratories, where under highly controlled conditions students are taught the hazards of the chemicals they use and methods of handling these substances safely.

The length of time of the exposure is also important in assessing the risk of chemical hazards, as is the amount of time that may pass before any symptoms of exposure to a substance may appear. Some chemicals may produce immediate symptoms whereas exposure to others may result in delayed effects. Responses may or may not be dependent upon the quantity of substance involved in the exposure. Exposures are either acute or chronic, and the related health effects are similarly termed acute or chronic. These effects are defined as follows:

- Acute health effects. Characterized by prompt or slightly delayed health effects, acute responses include burns, inflammation, allergies, or other immediate damage to organs such as eyes, lungs, or nervous system.

- Chronic health effects. Chronic effects are those that occur over a long period of time and whose effects on health are usually of an insidious nature or require a period of latency before overt disease develops. Chronic effects are characterized by reversible or irreversible cumulative damage to organ systems, and include carcinogenic effects.

As the cause-and-effect relationship of health hazards resulting from acute exposures to chemicals is usually very apparent, most laboratory workers take steps to avoid unnecessary or casual exposure to these hazards. Unfortunately, chemicals that produce chronic health effects are often treated more casually. Treating all chemical exposures in the same way can therefore benefit the indi- 
vidual by limiting exposure to chronic hazards. We will discuss the questions presented by acute and chronic exposures in more detail in Section 12.4.

Risk assessment should be an ongoing practice in the biomedical laboratory to evaluate all of the potential hazards from working with hazardous chemicals. Knowledge of chemical characteristics and methods of minimizing the potential hazards will help assure that unnecessary exposures to chemical hazards will not occur.

\subsection{Classes of Chemical Hazards}

Chemicals can be defined as hazardous based on their physical and chemical properties, and on their effect on material or personnel. Figure 12.1 shows the labels for some hazardous chemicals. Every hazard can be separated into two categories, which are not mutually exclusive: physical hazards which result in material damage, and health hazards.

- Physical hazards. A substance can be classified as a physical hazard if it is a flammable or combustible liquid, a compressed gas, an explosive, an oxidizer, or is unstable or water-reactive. Many physical hazards are also health hazards, but substances are grouped in this category because they have the capability of causing physical damage to material.

- Health hazards. Health hazards can be defined as substances that, if ingested, inhaled, or touched to the skin, can cause personal injury of an acute or chronic nature. Some substances that are health hazards can also be classified as physical hazards; the different hazard classifications can be ascribed to different properties of the same substance. For example, a corrosive substance will cause both personal injury and material damage by

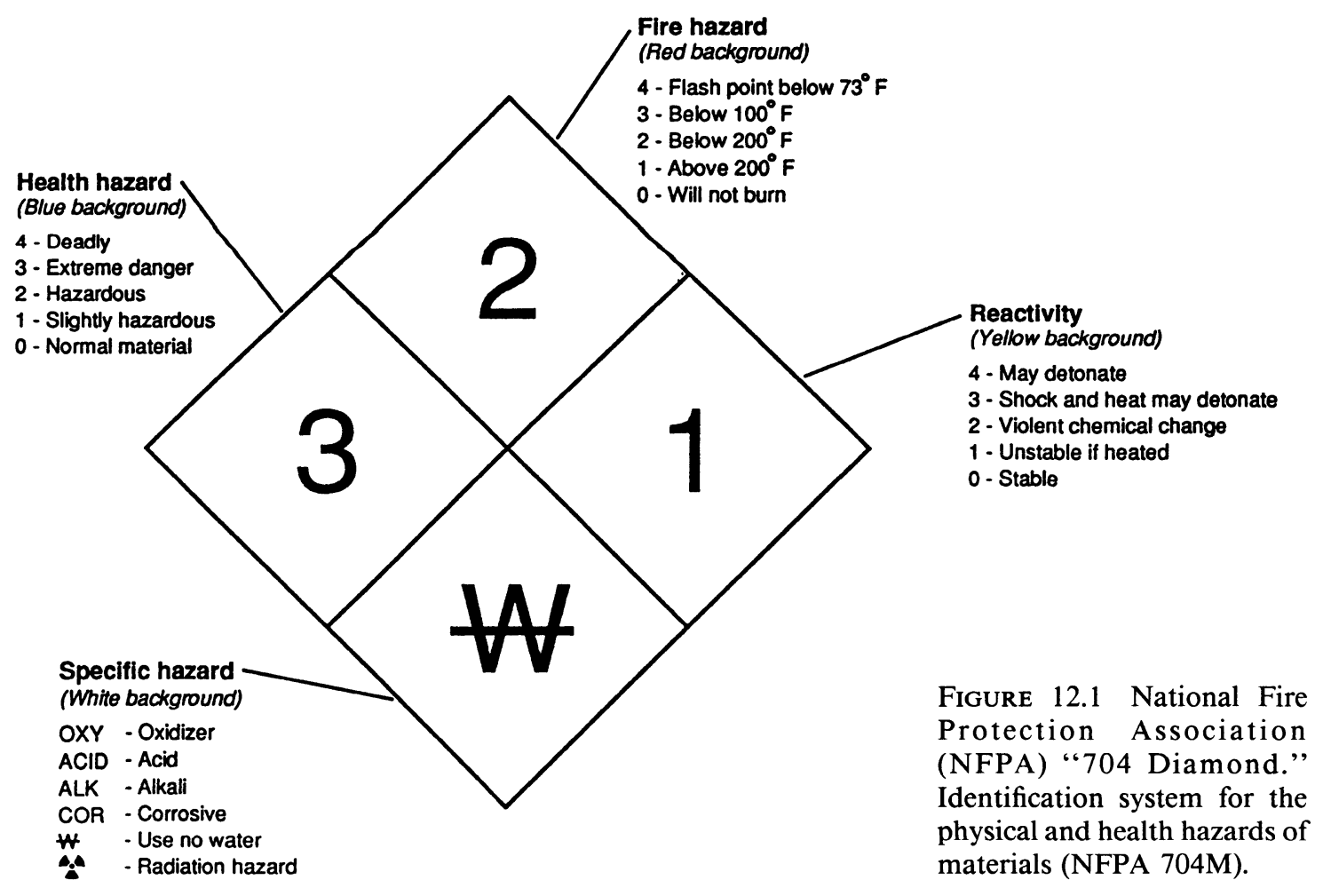


the same mechanisms, while a flammable liquid may have the additional property of being a carcinogen.

Health hazards include chemicals that are carcinogens, mutagens, teratogens, corrosives, irritants, or sensitizers, as well as other toxic materials such as poisons. They cause injury by damaging organs and tissues of the body. Some chemicals produce organ-specific damage while others, such as corrosives, produce general damage. Some of the chemicals which exhibit an organ specificity are listed here.

- Neurotoxins. Affect the nervous system, causing narcosis, behavioral change, loss of motor coordination. Examples: mercury, carbon disulfide, carbon tetrachloride, benzene, organometal compounds (84).

- Central nervous system depressants. Affect voluntary motor functions, causing loss of fine motor coordination, unconsciousness. Examples: methanol, ethanol, ether.

- Hepatoxins. Affect the liver, causing damage resulting in jaundice, liver enlargement. Examples: carbon tetrachloride, chloroform, heavy metals, toluene, mercury.

- Muscle poisons. Affect the muscles, causing muscle weakness and loss of function. Some substances affect smooth (involuntary) muscle. Example: barium salts. Some affect cardiac muscle, producing cardiac arrhythmias, angina, and muscle weakness. Examples: nicotine, halogenated hydrocarbons, carbon monoxide, potassium salts, nitrates. Cardiovascular poisons can cause coronary artery disease and hypertension. Example: carbon disulfide (80).

- Hematopoietic agents. Affect the blood system, including the blood-forming organs, leading to reduced blood functions and cyanosis, and loss of consciousness. Examples: carbon monoxide, cyanides, aniline, benzene, arsenic, fluoride.

- Pulmonary agents. Affect the lungs, trachea, and bronchi, causing cough, wheezing, shortness of breath, allergy, pulmonary edema, and emphysema. Restrictive lung diseases can also lead to congestive heart failure. Examples: asbestos, ozone, hydrogen sulfide, silica, chromium, beryllium (80).
- Nephrotoxins. Affect the kidney, causing edema and proteinuria. Examples: arsenic, halogenated hydrocarbons, oxalates, glycols, phenols.

- Epithelial hazards. Affect the skin and mucous membranes, causing burns, defatting of tissues, rashes, irritation. Examples: acids, phenol, ketones, trichloroethylene (83).

- Reproductive toxins. Affect the reproductive system, causing mutations, birth defects, and sterility. Examples: lead, polynuclear aromatic compounds, cadmium, ethylene oxide, ethylene glycol (81).

From this list it is obvious that the kinds of health hazards produced by chemicals are extremely diverse. The hazards will be covered in detail in Sections 12.3 to 12.10 .

\subsection{Hazards of Corrosive Chemicals}

Corrosive substances cause visible destruction or permanent changes in human skin tissue at the site of contact or damage skin through chemical reaction. Some of the most commonly used corrosives are listed in Table 12.3. The usual routes of exposure to chemical agents are inhalation, ingestion, and contact with body tissue. Corrosives can produce severe injury through any of these routes. Depending on their particular mode of action, some corrosive chemicals are more likely than others to produce especially severe damage through a particular route of exposure.

- Inhalation. The effects of inhalation exposure to corrosives can vary from severe but reversible irritation of the respiratory system to pulmonary edema, pneumonitis, complete destruction of the respiratory mucosa, or systemic poisoning. Examples: 1) Ammonia gas produces a severe irritation of the respiratory tract through alkaline caustic action. 2) Chlorine, phosgene, or nitrogen oxides cause an initial irritation of the respiratory tract, but these chemicals may also eventually produce a delayed or even relapsing pulmonary edema. 3) Ethyleneimine and 
TABLE 12.3 Common corrosive compounds

\begin{tabular}{|c|c|c|c|c|}
\hline $\begin{array}{l}\text { Acids and } \\
\text { anhydrides }\end{array}$ & Alkalies & $\begin{array}{l}\text { Halogens and } \\
\text { halogen salts }\end{array}$ & $\begin{array}{l}\text { Miscellaneous } \\
\text { compounds }\end{array}$ & $\begin{array}{l}\text { Organic halides, } \\
\text { esters and salts }\end{array}$ \\
\hline $\begin{array}{l}\text { Acetic acid (glacial) } \\
\text { Acetic anhydride } \\
\text { Chloroacetic acid } \\
\text { Chromic acid } \\
\text { Hydrochloric acid } \\
\text { Nitric acid } \\
\text { Perchloric acid } \\
\text { Sulfuric acid }\end{array}$ & $\begin{array}{l}\text { Ammonium } \\
\text { hydroxide } \\
\text { Potassium } \\
\text { hydroxide } \\
\text { Sodium hydroxide } \\
\text { Sodium peroxide }\end{array}$ & $\begin{array}{l}\text { Ammonium } \\
\text { bifluoride } \\
\text { Antimony } \\
\text { trichloride } \\
\text { Boron trichloride } \\
\text { Bromine } \\
\text { Calcium fluoride } \\
\text { Chlorine } \\
\text { Fluorine } \\
\text { Iodine } \\
\text { Lithium chloride } \\
\text { Potassium } \\
\text { hypochlorite } \\
\text { Sodium Fluoride } \\
\text { Vanadium } \\
\text { dichloride }\end{array}$ & $\begin{array}{l}\text { Ammonium sulfide } \\
\text { Cresols } \\
\text { Dimethyl sulfate } \\
\text { Ethylenimine } \\
\text { Hydrazine } \\
\text { Phenols } \\
\text { Sodium bisulfide }\end{array}$ & $\begin{array}{l}\text { Acetyl bromide } \\
\text { Allyl chloride } \\
\text { Benzyl bromide } \\
\text { Benzyl chloride } \\
\text { Chloroacetyl } \\
\quad \text { chloride } \\
\text { Ethylene oxide } \\
\text { Methyl } \\
\text { chloroformate } \\
\text { Propionyl chloride }\end{array}$ \\
\hline
\end{tabular}

similar chemicals can severely irritate mucosal membranes and also completely destroy the mucosal membranes of the pharynx, trachea, and bronchi.

- Skin contact. Skin contact (including ingestion) with corrosive chemicals causes a variety of injuries depending on the concentration and contact time of the substance. Short exposures and/or weak concentrations result in local irritation, while longer contact times or higher concentrations cause tissue burns, and absorption of the corrosive substance into deep tissues leading to systemic poisoning. Examples: 1) Concentrated mineral acids are powerful corrosives which cause immediate tissue burns. 2) Phenol is rapidly absorbed by the skin in solid, liquid, and vapor states. Skin absorption can occur even at low vapor concentrations. (Phenol will be discussed further below.) 3) Ethyleneimine in the liquid form is corrosive to the skin and is absorbed readily, resulting in systemic poisoning.

- Combined effects. Some corrosive chemicals can cause quite serious injury with equal facility to both the skin and the respiratory tract. Hydrofluoric acid, silicon tetrachloride, titanium tetrachloride, and vanadium oxychloride are typical chemicals in this category.
For our purposes, corrosive chemicals are divided into four different groups-acids, alkalis, dehydrating agents, and oxidizing agents. The hazards of each group are discussed in the following pages.

The strong, corrosive acids are generally defined as substances with a $\mathrm{pH}$ of less than two; however, $\mathrm{pH}$ in itself is not a reliable predictor of the relative corrosiveness of the substance. For example, concentrated citric acid (e.g., lemon juice) exhibits little corrosive action yet it has a low $\mathrm{pH}$. A substance's potential for causing tissue damage can be predicted more reliably by determining the amount of alkali needed to neutralize the substance (raise its $\mathrm{pH}$ to seven): the greater the amount of alkali, the greater the potential of the substance for causing tissue injury.

The severity of acid exposures depends on several factors: the type, concentration, and amount of acid involved, and the time and type of tissue exposure to the acid. Injury caused by acid burns usually involves a coagulation necrosis of the tissue with a precipitation of protein resulting in scab formation. This injury generally does not result in a deep penetration of tissues.

The hazards of the most commonly used corrosive acids are listed below: 
- Sulfuric acid. This substance, besides being classified as a corrosive, is a moderate health hazard. Fuming sulphuric acid (oleum) produces sulfur trioxide vapors which are extremely irritating to mucous membranes. Mixing concentrated sulfuric acid with water generates considerable heat, so caution must be used when diluting the acid. Always add the acid to water-not water to acid-while agitating constantly. Use a thermally resistant container (not the acid bottle) to reduce the chance of breaking the container. Place the mixing container into a second container, such as a tray or battery jar, to contain any spills should a break occur.

- Nitric acid. This substance is a powerful corrosive and a serious health hazard. The concentrated acid is about 70 percent $\mathrm{HNO}_{3}$ in water and evolves $\mathrm{NO}_{2}$ vapors which can cause noticeable throat irritation at 62 parts per million (ppm). Repeated exposure to the vapor can result in chronic bronchitis. Exposures to vapors of a concentration of 200 to $700 \mathrm{ppm}$ in air can result in a rapidly fatal pulmonary fibrosis. Injury caused by inhalation of oxides of nitrogen may not appear for 24 to 48 hours after exposure, with the first symptoms being pulmonary edema. Nitric acid burns are slow-healing and may result in scarring of tissue. Organic materials may ignite upon contact with the acid.

- Hydrochloric acid. Classified as a moderate health hazard, hydrochloric acid vapors cause irritation of the upper respiratory tract. Higher concentrations of the vapor cause lung irritation. While hydrochloric acid is not flammable, hydrochloric acid solutions attack many metals, evolving hydrogen gas which can ignite. Other strong mineral acids behave in a similar fashion.

- Chromic acid. This chemical is extremely toxic as well as being a very powerful oxidizing agent. A popular glassware cleaning solution is made by combining sulfuric acid with a chromate salt mixture, thus forming chromic-sulfuric acid. Improper or careless use of this substance is extremely hazardous because of the corrosiveness of the liquid as well as its toxicity. Furthermore, if the acid mixture is contaminated with chloride ion, the substance can react to produce volatile chromyl chloride, a potent carcinogen (250). In order to avoid this the acid cleaning solution must be kept free of contaminants by rinsing all articles before placing them into the acid bath, by keeping the acid solution cold and covered, and by using it in a fume hood or with adequate ventilation.

- Hydrofluoric acid. Hydrofluoric acid is one of the most difficult chemicals to handle. The acid is extremely reactive and is very damaging to the skin and the underlying tissue. It can cause severe burns to the skin and underlying tissue, destroy blood vessels, and even penetrate to the bone. In tissue burns involving destruction of capillaries and other vascular tissue, gangrene may develop. Even dilute solutions may cause severe injury, although immediate pain and/or injury may not be apparent. A 0.037 percent solution of hydrofluoric acid can destroy the epithelium. Failure to immediately treat even superficial contact with this acid may cause extremely painful, slow-healing ulcers. It is imperative that all hydrofluoric acid burns receive immediate medical attention.

The corrosive alkalis are strong basic (caustic) substances that can attack tissues, other organic substances, and metals, although alkali reactions with metals are considerably slower than reactions with acids. Corrosive alkalis are generally classified as materials with a pH of 11.5 or greater; however, as with acids, the $\mathrm{pH}$ of an alkaline compound in itself cannot reliably indicate its relative hazard. Even very dilute alkalis can produce severe burns. A 3.8 percent sodium hydroxide solution can produce a necrosis of the mucosa and submucosa of the esophageal wall.

As discussed above in relation to acid burns, the degree of tissue damage resulting from an alkali burn depends upon the type of alkali, its amount and concentration, and upon the length of time and the type of tissue exposure. However, all other factors being equal, alkalis are noted for their ability to produce far more damage to tissue than acids. While acids tend to produce coagulation and scab formation, alkalis produce a liquification necrosis, de- 
naturing protein, and a resulting loosening of tissue that allows the alkali to penetrate deeper into the tissues, causing deeper and more extensive injuries than acids produce.

Many alkalis are quite hygroscopic and exhibit high heats of solution. As with sulfuric acid, always add the caustic to water rather than the opposite to avoid a violent reaction. Some examples of caustic alkali compounds include sodium, potassium and ammonium hydroxide, and sodium peroxide.

Phenol exhibits some properties usually associated with acids and also possesses health hazard properties similar to alkalis. Exposure to phenol is most likely to occur through skin contact rather than ingestion or inhalation. This is fortunate since ingestion of phenol, although very unlikely, is extremely dangerous. Ingestion can cause symptoms of muscular weakness, cyanosis, tremors, convulsions, and collapse a few minutes after ingestion of the chemical. Death is rapid, and usually results from respiratory collapse. Laboratory and industrial accidents involving splashes of phenol onto the body occur with appreciable frequency. Contact with the concentrated chemical over more than 20 percent of the body for more than one to two minutes can have the same effect as ingestion. Inhalation of vapors can produce the same symptoms as severe skin exposures. Skin contact with phenol can result in local skin damage, including eczema, inflammation, discoloration, sloughing of tissues, and necrosis. Obviously, this chemical is a highly toxic systemic poison, and any exposure should receive immediate medical attention.

The dehydrating agents are the third major group of corrosive chemicals. Because these compounds have a very high affinity for water and possess a high heat of solution, they create a large amount of heat when water comes into contact with them. This reaction can cause severe thermal burns to the skin, and in addition causes extensive dehydration of tissues. Examples of dehydrating agents include concentrated sulfuric acid, sodium hydroxide, phosphorus pentoxide, and calcium oxide. When mixing these substances with water, al- ways add the compound to water to avoid violent reactions that may cause spattering.

Finally, strong oxidizing agents, such as perchloric acid, nitric acid, and chromic acid, pose another hazard in addition to their extreme corrosiveness. Because these substances can cause a fire or explosion hazard upon contact with organic compounds or any oxidizable substance, extreme care is required in their handling and storage.

The category of corrosives is broad and includes a great diversity of materials, as we have seen. Although these substances differ greatly in chemical structure, they have in common the ability to produce significant tissue injury. Some of them also pose other kinds of health hazards and will be discussed again in this chapter.

\subsection{Hazards of Toxic Chemicals}

Toxic substances include poisons, irritants, and asphyxiants. They differ from corrosive chemicals because they do not react directly with human skin tissue. The health effects of a toxic chemical result from its interfering with metabolic processes. The toxic effects of a chemical depend primarily on the factors outlined below:

- Characteristic properties of the substance

- Concentration of the substance

- Routes of entry into the body

- Amount absorbed

- Duration of exposure to the substance

- Age, weight, and general health of individual exposed

- Individual susceptibility to injury

Many of these factors are self-evident, and some have been previously discussed. Some of the factors that have the greatest significance in producing a chemical exposure injury are discussed below.

\section{Routes of entry}

Since chemicals can enter the body through ingestion, inhalation, or skin absorption, assessments of exposure hazard to toxic chem- 
icals must consider all routes of entry. While all routes of entry of toxic chemicals are important, many laboratory workers tend to emphasize the hazards associated with inhalation and ingestion of chemicals and ignore the danger of skin absorption of these substances. Therefore, we will discuss this route first.

In the previous section on corrosive chemicals we discussed the effects of corrosives on the skin. While corrosive substances can be absorbed into the skin, they do so mainly by damaging the skin and underlying tissues. Skin absorption of chemicals attains its greatest significance in reference to organic solvents (101), such as benzene, because many of these substances can cross the intact skin barrier while leaving little, if any, trace of the exposure. Table 12.4 lists some of the common chemicals that are easily absorbed, and some others are shown in Appendix 2. Also, hazards arising from improper use of organic solvents, such as using these substances for handwashing and for cleaning tools, not only promote

TABLE 12.4 Examples of some chemicals easily absorbed through the skin

\begin{tabular}{ll}
\hline Acrylamide & Hydrogen cyanide \\
Aniline & Mercury \\
Benzene & 2-Methoxyethanol \\
Benzidine & Methyl acrylate \\
Bromoform & Methyl bromide \\
Butylamine & o-Methyl cyclohexanone \\
Carbon tetrachloride & Methylaniline \\
Chlorodiphenyl (PCB) & Methylhydrazine \\
$\beta$-Chloroprene & Nicotine \\
Cresol & p-Nitroaniline \\
1,2-Dibromoethane & Nitrobenzene \\
Dichloroethyl ether & p-Nitrochlorobenzene \\
Dimethyl acetamide & N-Nitrosodimethylamine \\
Dimethylaniline & Nitrotoluene \\
Dimethylformamide & Phenol \\
1,1-Dimethylhydrazine & Phenylhydrazine \\
Dimethylsulfoxide & Picric acid \\
(DMSO) & Propylenimine \\
Dinitrobenzene & $1,1,2,2-$ Tetrachloroethane \\
Dinitrotoluene & Tetraethyl lead \\
Dioxane & o-Toluidine \\
Epichlorohydrin & $1,1,2-T r i c h l o r o e t h a n e$ \\
2-Ethoxyethylacetate & Trichloronaphthalene \\
Ethylenimine & Trinitrotoluene \\
Hexachloroethane & Xylidine \\
Hydrazine & \\
\hline & \\
\hline & \\
\hline
\end{tabular}

skin absorption but can lead to mechanical skin irritation, dermatitis, and increased absorption through traumatized hand, wrist, and arm tissues. Except for this problem, the skin ordinarily provides an effective barrier against the penetration of toxic substances, because relatively few toxic substances can actually be absorbed through intact skin in dangerous amounts (132). Although the skin barrier provides a high degree of resistance to many chemicals, others, such as lipid-soluble substances, can penetrate the skin more readily. In addition, different parts of the body can absorb chemicals more efficiently than others. For example, the scalp can absorb about four times as much pesticide as the forearm, while the forehead is capable of absorbing almost twice as much as the scalp can absorb (277a).

To reduce the hazard of skin exposure, the use of protective gloves should be required when working with chemicals, and the practice of personal hygiene in keeping the skin clean is of paramount importance.

Laboratory accidents involving ingestion of chemicals are far less common than accidents involving the other routes of exposure to chemicals-inhalation and skin absorption. If an exposure does occur, generally the quantity ingested is small because the exposure is through contamination of hands, cigarettes, or food. However, larger quantities of toxic materials can be ingested in a mouth-pipetting accident. Fortunately, in many cases involving chemical ingestion, the full toxic potential of the chemical is not realized. This fact is unexpected and is usually a result of the following factors. After entering the alimentary system, the chemical is diluted by mixing with saliva, food and water, which limits its absorption. The chemical can also react with the substances present in the digestive tract, mitigating its toxicity. The intestinal tract also is selective in absorption of substances, and many toxic chemicals are not efficiently absorbed. Finally, the blood that contains substances absorbed from the gastrointestinal system is immediately carried to the liver, where many toxic substances are detoxified. For all these reasons, chemicals absorbed through the skin or substances absorbed by inhalation 
pose a significantly greater hazard than those that are swallowed (132).

Of the three primary routes of entry of toxic chemicals into the body, inhalation into the respiratory tract is by far the most important $(132,437)$. Toxic substances may be present in air as particles, vapors, or gases (see Section 2.7). Particles may be present as dusts, aerosols (droplets of suspended liquids), or fumes (very small solid particles). The rate of entrainment of toxic chemical particles in the respiratory tract is highly dependent on their size, shape, and density. Particles greater than one to two micrometers $(\mu \mathrm{m})$ in diameter are not important in the production of particulate lung injury, primarily because such particles do not stay suspended in air long enough to be breathed, nor are they able to pass through the passages of the upper respiratory tract.
This is shown in Figure 12.2. Such particles are usually captured on the epithelium of the nasopharynx, where ciliary action either expels them from the nose or, in combination with secretions, carries the particles into the alimentary tract. In contrast, particles smaller than one micrometer but greater than $0.3 \mathrm{mi}-$ crometers in diameter are able to pass through the respiratory passages and may lodge in some of the smaller passages or in the alveoli themselves, where the particle will be exposed to phagocytosis or solubilization by the blood. Substances that resist removal by one of these mechanisms may remain at the site where they lodged. Particles of less than about $0.3 \mathrm{mi}-$ crometers, on the other hand, are generally too small to be retained in respiratory passages and are inhaled and expelled with each breath. Therefore, particles from 0.3 to 2 micrometers

Percent deposited in respiratory tract (\%)

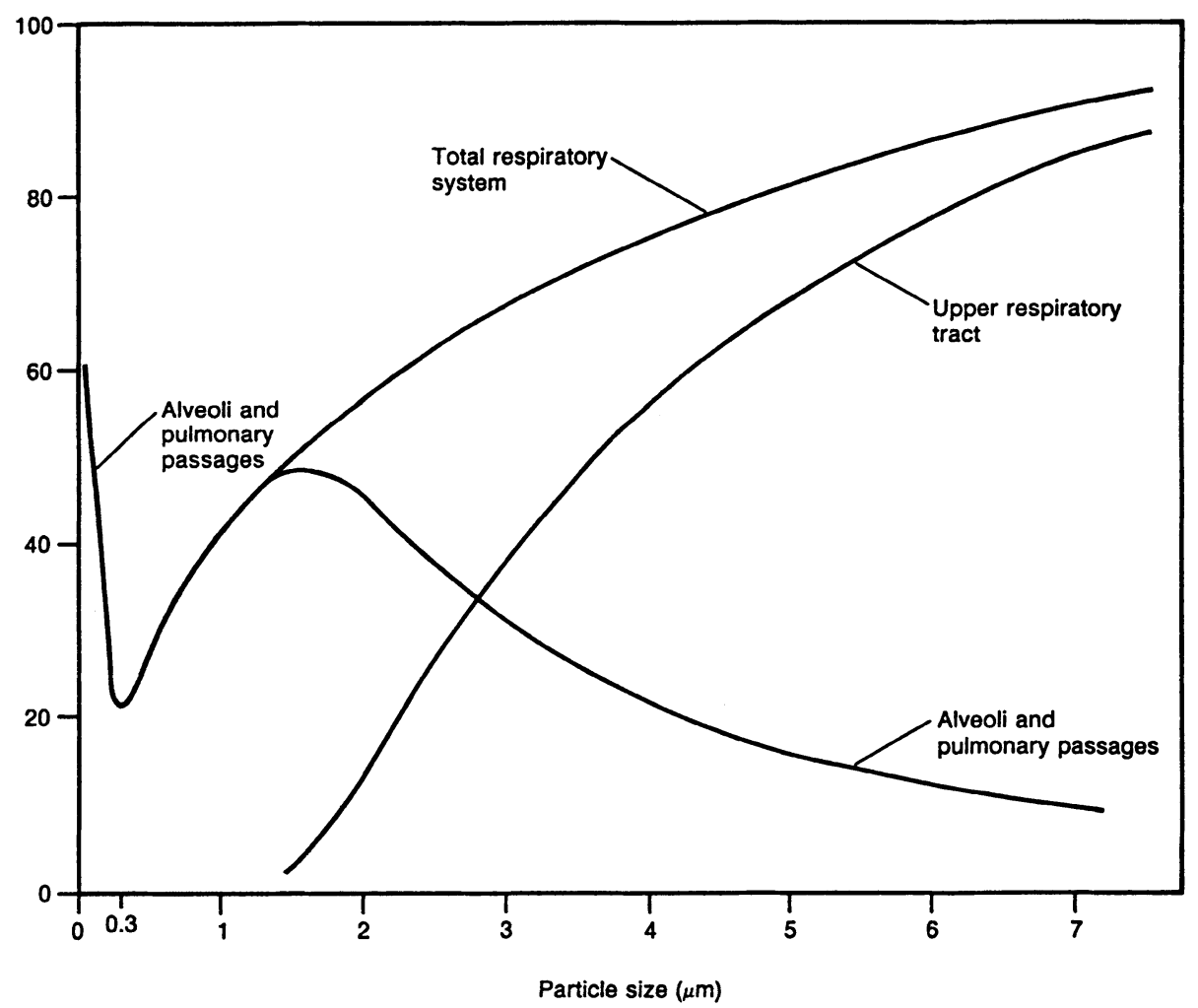

FIGURE 12.2 Rate of respiratory retention. Small particles tend to be retained deep in the lungs, in the alveoli and pulmonary passages, while large particles are retained in the upper respiratory tract. Adapted from (202). 
in diameter are most important in inhalation injury.

Toxic substances can affect the pulmonary system in two major ways: the depositing of particles in the alveoli or in pulmonary passages leads to irritation, inflammation, fibrosis, allergic sensitization, or even malignancies; the absorption of chemicals from pulmonary tissue and solubilization in the blood stream leads to systemic poisoning. The lungs are extremely effective at absorbing chemicals entrained in the respiratory tract. The total alveolar surface area is about 70 square meters and the capillary network surface area is about 140 square meters (162). When one considers that, under average conditions of exertion, an adult breathes about ten cubic meters of air in an eight-hour working day, the total surface area in the lungs available for absorption of chemicals tends to make this route of exposure exceptionally efficient and therefore quite dangerous.

Toxicology is the study of the potential of a substance to cause a harmful effect to animals and humans by describing the effect and the conditions under which the effect takes place. Simply stated, toxicology is the study of the nature and action of poisons. A substance is said to be toxic if it has the ability to produce injury at a susceptible site on or in the body. Toxicology is concerned with several factors that influence the toxicity and mode of action of a toxic substance. The most important factors are the dose-response relationship, the route of entry of the substance into the body, and the time course of exposure.

- Dose-response relationship. Determination of the toxicity of a substance can be made only when that substance comes into contact with a living biological system, such as humans, animals, or tissue cultures. Chemicals that are normally considered nontoxic can produce a toxic effect if they are absorbed in sufficient quantity. Therefore, the toxic effect of a given substance is dependent upon the dose or amount of the substance and the response it produces in a biological system.

- Route of entry. As discussed earlier, the route of entry of a toxic substance into the body plays a major role in its effect in the individual.

- Time course of exposure. Also as covered earlier, exposure to toxic substances can be classified as either acute or chronic. Acute toxicity is characterized by rapid absorption of the chemical, through a single exposure or an exposure occurring within 24 hours (132). Chronic exposure, on the other hand, is characterized by repeated exposures over a longer period of time measured in days, months, or years. Some substances to which an individual is chronically exposed are not excreted efficiently and therefore accumulate in the body. These cumulative poisons do not exhibit an overt effect until a critical body burden is reached. Also, when two or more hazardous substances are absorbed at the same time, the resulting effect on the individual can be greater than just the sum of the expected effects based upon the toxicity of the individual substances (108). This is known as a potentiating or synergistic effect.

Measuring and quantifying toxicity is a complicated and difficult task. Studies to determine the toxicity of chemicals usually utilize laboratory animals or tissue culture systems; the data obtained is then extrapolated to humans. Although data obtained from culture systems can show physiological effects at the cellular level, this information is difficult to extrapolate to human systems, but it is most successful at predicting the mutagenicity of a toxic chemical (see Section 12.7). Animal studies, on the other hand, allow the determination of whole-body physiological effects of a substance, which produces more reliable extrapolations than tissue culture systems (see, for example, (165)).

Toxicology studies are often performed on animals in order to establish an average lethal dose (LD) of toxic chemicals, and to determine the mode of action of the poison, including target organ, physiological action, method of entry or exposure, or the effect of prior exposures. Statistical methods used in toxicology studies determine important measures of the toxicity of a substance: the lethal dose that will kill 50 percent of the test animal 
group within 30 days following a single exposure (the $\mathrm{LD}_{50 / 30}$ ), or the concentration of an airborne substance that is lethal for 50 percent of the test group within 30 days (the $\mathrm{LC}_{50 / 30}$ ).

Toxicity studies in animals, together with experimental human exposure studies and industrial experience, form the basis for the guidelines that have been formulated limiting exposure to toxic chemicals in the workplace. In the United States these recommended occupational exposure limits (Threshold Limit Values or TLVs) are prepared and published each year by the American Conference of Governmental Industrial Hygienists (ACGIH) (11). The TLVs indicate the limiting conditions below which the best evidence indicates that individuals can receive chronic or acute exposures with no adverse effect. The TLVs are advisory in nature, and are not legal standards, although some of these standards do eventually become incorporated in laws or regulations (see below). There are three different forms of TLVs.

- Time-weighted average form. The TLV-TWA is the average time over a standard work day of eight hours or work week of 40 hours of an individual's exposure to a hazardous substance over a long period of time without adverse effect. The average exposure is determined by sampling for the agent throughout the time period.

- Short-term exposure limit form. The TLVSTEL represents the maximum concentration to which individuals can be exposed for a period of up to fifteen minutes continuously without adverse effect. No more than four such exposures are permitted per day, at least sixty minutes must elapse between each such exposure, and the TLV-TWA must also not be exceeded.

- Ceiling value form. The TLV-C is the concentration of an agent that must never be exceeded, even for an instant.

In the United States, the Occupational Safety and Health Administration (OSHA) has established legal standards for some toxic substances. Title 29, Code of Federal Regulations, Part 1910.1000 contains tables of Permissible Exposure Limits (PELs). The PEL values are derived in part from TLV data published by ACGIH, but are not as up-to-date. Appendix 2 contains TLV data for selected chemicals.

\section{Fate of toxic substances in the body}

There are several different ways the body deals with toxic substances depending on factors including the chemical nature of the substance, its physical state, and the site of absorption. Other factors, such as how the substance is handled in the body or interacts with body functions, also are important. The four most important methods are described in the following list:

- Storage. Some toxic substances, such as heavy metals, are stored in tissues (lead is stored mainly in bones, whereas mercury is primarily stored in the kidneys) where they may be retained for considerable time. The material does not undergo chemical transformation, and toxic effects result from direct interference with metabolism or with the anatomical structure and its biologic function, after a critical body level of substance is achieved. This can occur when the storage site (the storage organ) for the substance becomes saturated, whereupon the toxic material can become mobilized into the circulation, where it can interact with the critical organ and produce toxic effects. The critical organ is the first to attain a concentration where its function will be affected. We will discuss the critical organ concept below.

- Tolerance. Repeated low-level doses of some chemicals can alter certain body responses which otherwise would be observed when an acute dose is administered. The damage still occurs, but the symptomology becomes altered. A good example of this phenomenon can be found in individuals who abuse alcohol (ethanol). The body is said to become tolerant to some of the effects of the chemical.

- Biotransformation. Some materials can undergo chemical changes within the body, mainly in the liver, in an attempt by the body 
to make the substance more oxidizable so that it can be excreted more readily. This process is known as detoxification, but the resulting metabolites are not necessarily less toxic than the original compound. The metabolites of some compounds are more highly toxic than the parent compound (110). For example, methanol is transformed to formaldehyde, which damages the optic nerve, and aniline is converted to p-aminophenol, a potent methemoglobin-forming agent that can cause a functional anemia.

- Excretion. Excretion of toxic substances is a function of a critical balance between intake, body burden, and turnover in the storage tissues. Assuming repeated exposure to a substance, there is a steady increase of concentration until the storage tissues are saturated or at least until uptake and excretion are equal. For some toxic substances, such as carbon monoxide, the substance can be excreted completely between successive days of low-level exposure.

Most chemicals have longer residence times in the body than carbon monoxide. The term used to denote the length of time that 50 percent of the body burden of a substance is excreted is the biological half-life. The biological half-life of a compound can vary from one tissue to another. Thus, the biological half-life of lead in bone is between ten to twenty years, but in blood and soft tissues it is in the 30day range.

After long-term exposure to a toxic substance is stopped, or after a single dose is completely absorbed, the body burden will decline as a result of excretion. Substances can be excreted through the three primary modes of entry, respiratory tract, alimentary tract, and skin, but the primary route of excretion is in the urine. Gases not metabolized in the body are in general excreted by exhalation, and some solvents that are absorbed through the skin or ingested and absorbed into the blood can also be excreted by respiration. Excreting of chemicals in the feces is limited to unabsorbed substances which were orally ingested, or to compounds which, after processing and detoxification in the liver, are secreted into the bile which is then passed into the intestinal tract. Substances may also be excreted via the sweat glands. However, since one-quarter of the blood volume circulated per unit time is circulated through the kidneys, and about half of this volume undergoes the first filtration step, excretion in the urine is the most important mechanism of excretion of chemical toxins. This is why substances whose site of action involves the kidneys, such as heavy metals or chlorinated hydrocarbons, can be so damaging. Impairment of the kidneys, the body's primary means of excreting toxic metabolites, will rapidly affect the health.

\section{Threshold and critical organ concepts}

We have mentioned the term critical organ earlier, and used the term threshold in our discussion of TLVs. Let us now closely examine these concepts in terms of the actual mechanism of damage produced by toxic chemicals. After being absorbed either in a single dose or chronically over a period of time, a chemical substance typically becomes concentrated in various tissues. Some of the tissues (storage sites or organs) that take up the toxic substance might do so preferentially with little toxic effect, as fatty tissue does for storage of nonpolar compounds. Up to a certain level of storage in the body, the toxic chemical will have no or little observable effect on an organ. After this point, known as the threshold, is reached any additional amount of the toxic chemical will begin to exhibit an effect. Also, as concentrations in the body increase, one organ will be the first one to attain a level that can affect its function. This organ is referred to as the critical organ for that substance. However, for any one substance, there may be more than one critical organ, depending on the dose, route of exposure, and length of exposure.

Toxicology studies attempt to determine both the threshold and the critical organs for toxic substances. The resultant information can be used to ensure that levels of exposures are low enough to avoid reaching the threshold and damaging the critical organ. 


\subsection{Hazards of Chemical Sensitizers and Irritants}

The study of chemical sensitization is a special category of toxicology. Certain chemicals have the capacity to cause allergic sensitization, which can result in a severe allergic reaction to the chemical upon subsequent exposure. Table 12.5 lists some of the chemicals that do so, and Table 20.4 lists some common sensitizers. The disease can be severely disabling, and in England occupational dermatitis caused by chemical sensitization or by irritants is legally defined as a disabling occupational injury. In the United States, about half of all occupational illnesses involved skin disorders (469), and they are a significant occupational health problem in terms of lost worker productivity, medical care costs, and disability payments (284). Dermatitis (irritation of the skin) can be a major problem in the laboratory, in occupations where chemicals are utilized, and in manufacturing and pilot plants. Dermatitis can be caused by any of the following four different mechanisms:

- Mechanical injury. Mechanical abrasion of the skin, or fine particles forced into the skin, may result in rashes or inflammation of the skin.

- Primary irritants. This category of irritants causes dermatitis by direct action of the substance on the skin at the site of contact. This may be produced by several different means. Chemicals such as alkalis or sulfides dissolve

TABLE 12.5 Examples of chemicals that produce allergic sensitization

\begin{tabular}{ll} 
Acrylamide & Epichlorohydrin \\
Aluminum picrate & Ethylenediamine \\
Amatol & Formaldehyde \\
2-Aminophenol & $1,2,3,4,5,6-$ \\
Ammonium thioglycollate & Hexachlorocyclohexane \\
Aniline & Isocyanites \\
Arsenic compounds & Mercury compounds \\
Bichromates & Nickel compounds \\
Butadiene dioxide & Phenols (certain \\
Chromium compounds & compounds) \\
p-Dichlorobenzene & \\
\hline
\end{tabular}

the skin keratin, while chemicals such as petroleum are keratogenic in action. Some substances, such as organic solvents, dissolve or emulsify fatty tissue, while substances such as heavy metal salts precipitate proteins. Other damage to skin can be caused by oxidizing agents (some inorganic acids), protein denaturants (some inorganic and organic acids), and dehydrating agents (various corrosive chemicals, anhydrides, and hygroscopic compounds, see Section 12.3).

- Sensitizers. There are two basic types of sensitization reactions: dermatitis and asthma. There are differences between injuries caused by irritants and those resulting from contact with sensitizers. Irritants produce damage by directly reacting with skin or mucous membrane tissues to produce immediate injury such as inflammation. Sensitization occurs when a substance activates the immunity response of the skin or epithelial tissues. This activation results in a later injury when the exposure is repeated. The resulting injury is characterized by rashes, inflammation, angioedema, anaphylaxis (73), and if the respiratory tract is involved, asthma (64). Furthermore, the chemical hydrazine has been found to induce a systemic lupus erythematosus-like disease (370). While allergic sensitivity is for the most part an inherited characteristic, prolonged contact with a sensitizing agent that functions as an allergen will greatly increase the chance that even a normal individual will have a reaction to the substance (214).

- Photosensitizers. This group of chemicals has the capability of sensitizing the skin to ultraviolet radiation. When the chemical is absorbed, usually through skin contact (although ingested chemicals such as certain drugs can also produce this effect), the ultraviolet light in sunlight interacts with the substance and the tissue to produce inflammation.

The most important method of limiting injury caused by sensitizing agents, as well as all toxic chemicals, is avoiding exposure to the substance. This is best achieved through the use of gloves and/or protective apparel, as the 
situation dictates. Because of the very wide variety of chemicals that can produce allergic reactions, no comprehensive list is available.

\subsection{Hazards of Chemical Carcinogens}

Chemical carcinogens are substances that can produce cancer in humans and/or animals. Table 12.6 lists some chemicals that are known to be carcinogenic as well as some that are suspected to be so. Cancer is currently the second leading cause of death in the United States, according to the most recent government reports. During the past 80 years, the incidence of cancer has grown about five-fold: in 1900, about 4 percent of deaths were caused by cancer, but in recent years this proportion has grown to about 20 percent (247). Despite the fact that improvements in medical care during this period contributed to curing many heretofore fatal diseases and otherwise helped in increasing life expectancy, the rate of increase of cancer incidence rose at a faster rate than increasing life expectancy would predict. A significant amount of this increase in cancer can therefore probably be attributed to environmental factors.

About 4 percent of cancer incidence apparently is directly related to occupational exposure to carcinogenic agents. In addition, according to a recent publication, smoking and the use of tobacco account for 30 percent of cancer incidences, viruses and infections, 10 percent; sexual practices (also probably produced by viruses), 7 percent; environmental and medical radiation exposure, 1 percent; abuse of alcohol, 4 percent; heredity, 2 percent; food additives, 1 percent; diet, about 30 percent; unknown factors, at least 5 percent; and environmental pollution (not occupational exposure), 2 percent (128). Although some researchers report that the percentage of cancers caused by environmental pollution and occupational exposure exceed the 6 percent listed above (138), most experts agree that occupational exposure to carcinogens is a major cause of cancer in certain occupations (15,
138). Therefore, there is a clear need for improving the safety of workers in these occupations, and in addition to the normal laboratory precautions for chemicals, other operational controls and guidelines for handling and disposing of chemical carcinogens may be necessary. One such policy is described in NIH Guidelines for the Laboratory Use of Chemical Carcinogens (482).

\section{Factors influencing carcinogenesis}

Evaluating the risks of exposure to chemical carcinogens can be extremely difficult because, unlike the controlled conditions that can be established for test animals, humans are routinely exposed to a wide variety of environmental agents of differing carcinogenic potential. Furthermore, interactions between carcinogens can result in at least three different effects. If two carcinogenic substances interact, there can be a direct additive effect, where each compound contributes to tumor interaction in direct proportion to its individual tumorigenic activity. Conversely, the tumorigenic properties of the substances may interfere with each other, an effect called antagonism. Or the compounds may each contribute to the tumorigenic activity of the other substance, making each more effective than they would be individually. This property is referred to as synergism.

If one of the interacting chemicals is itself not a carcinogen, there are also at least three possible results. Of course, one possible outcome of the interaction is that no additional effect will be noticed, and that the tumorigenic properties of the carcinogen will remain unchanged. Two other possibilities include inhibition of the carcinogen to reduce its capability to induce tumors, and conversely, promotion of the tumorigenic properties of the compound. A promotor (or cocarcinogen), itself not carcinogenic, has the property of being able to enormously increase the carcinogenic activity of weak carcinogens, or to increase the efficiency of extremely small doses of strong carcinogens. The carcinogen whose activity is thus potentiated is called an initiator. Such cross-reactions between chemicals in tumori- 
TABLE 12.6 Some chemical carcinogens and suspected carcinogens

\section{Aflatoxins}

Aliphatic halides

Carbon tetrachloride

Chloroform

1,2-Dibromo-3-chloropropane

Ethylene dibromide

Vinyl chloride*

Aminofluorene derivatives

$\mathrm{N}$-Acetoxy-2-fluorenylacetamide

N-2-Fluorenylacetamide (2-AAF)*

Aromatic amines and related compounds

4-Aminobiphenyl*

Benzidine*

3,3'-Dichlorobenzidine

3,3'-Dimethoxybenzidine

3,3'-Dimethylbenzidine

4,4'-Methylene bis(2-chloroaniline) (MOCA)

1-Naphthylamine*

2-Naphthylamine*

4-Nitrobiphenyl*

m-Toluenediamine

Aromatic hydrocarbons

Benzene*

Aryl halides

Polychlorinated biphenyls (PCB)

Aziridines

Dimethylethylenimine

Ethylenimine*

Propylenimine

Azo- and azoxy derivatives

o-Aminoazotoluene

Cycasin

Diazomethane

p-Dimethylaminoazobenzene*

3'-Methyl-4-aminoazobenzene

Carboxylic acid derivatives

Ethionine

$\beta$-Propiolactone*

Urethane

Chloromethyl ethers

bis(Chloromethyl) ether*

Chloromethyl methyl ether*
Ethers, oxides, and epoxides

Diepoxybutane

p-Dioxane

4-Nitroquinoline-1-oxide

Hydrazines

1,1-Dimethylhydrazine

1,2-Dimethylhydrazine

Hydrazine

Methylhydrazine

Procarbazine

Nitrofuran derivatives

$\mathrm{N}$-[4-(5-Nitro-2-furyl)-2-thiazolyl]-formamide

Nitrogen mustards

Chlorambucil

Uracil mustard

Nitrosamides

$\mathrm{N}-$ Methyl-N'-nitro-N-nitrosoguanidine

$\mathrm{N}-\mathrm{Nitroso}-\mathrm{N}$-ethylurea

$\mathrm{N}$-Nitroso-N-ethylurethane

$\mathrm{N}-\mathrm{Nitroso}-\mathrm{N}$-methylurea

$\mathrm{N}-\mathrm{Nitroso}-\mathrm{N}$-methylurethane

Nitrosamines

1,4-Dinitrosopiperazine

N-Nitrosodibutylamine

N-Nitrosodiethylamine

N-Nitrosodimethylamine*

N-Nitrosodipropylamine

$\mathrm{N}-\mathrm{Nitrosopiperidine}$

Polycyclic aromatic hydrocarbons

Benz[a]anthracene

Benzo[a]pyrene*

7-Bromomethyl benz[a]anthracene

7,12-Dimethylbenz[a]anthracene

3-Methylcholanthrene

Sulfonic acid derivatives

Bromoethyl methanesulfonate

Ethyl methanesulfonate

Methyl methanesulfonate

1,3-Propane sultone

*Carcinogenic chemicals regulated by OSHA.

genesis are at best incompletely understood, but these mechanisms probably play a major role in environmental and occupational carcinogenesis.

Other factors that influence the rate of induction of tumors include various endogenous (host-related) and exogenous (environmentrelated) factors. The endogenous factors include age, state of health, nutritional status, genetic predisposition, hormonal balance, and condition of immune system, while the exogenous factors include the dose of carcino- 
gen, the type of exposure, the presence of inhibitors or promotors, and exposure to radiation and immunosuppressive agents. Figure 12.3 shows how some of these factors are interrelated. In this figure, initiation represents the production of transformed, or tumor, cells that may either remain dormant or begin to proliferate, depending on the absence or presence of stimuli, such as promotors or additional doses of carcinogens. Initiation progresses to expression only if tumor cells begin to proliferate irreversibly. As Figure 12.3 shows, a very wide range of factors, both endogenous and exogenous, affect the progress of carcinogenesis. Thus it can be seen that tumorigenesis is a highly complex process and many opportunities for reversal of some effects exist, further complicating studies. Two of the more important metabolic processes related to tumorigenesis, metabolic activation and detoxification of carcinogens, will be discussed later in this section.

\section{Assays for carcinogenicity}

Chemicals commonly are screened for carcinogenic potential using two basic types of tests, animal bioassay and in vitro assays. Animal bioassays for carcinogenic activity are most commonly conducted in mammalian species, such as rats, mice, and hamsters. The second type of assay using in vitro procedures screens either for transformation in mammalian cells or for the mutagenic potential of a chemical in a bacterial system after metabolic activation of the test substance (130). Other test systems, such as dominant-lethal mutation tests, translocation tests that screen for chromosomal ab-

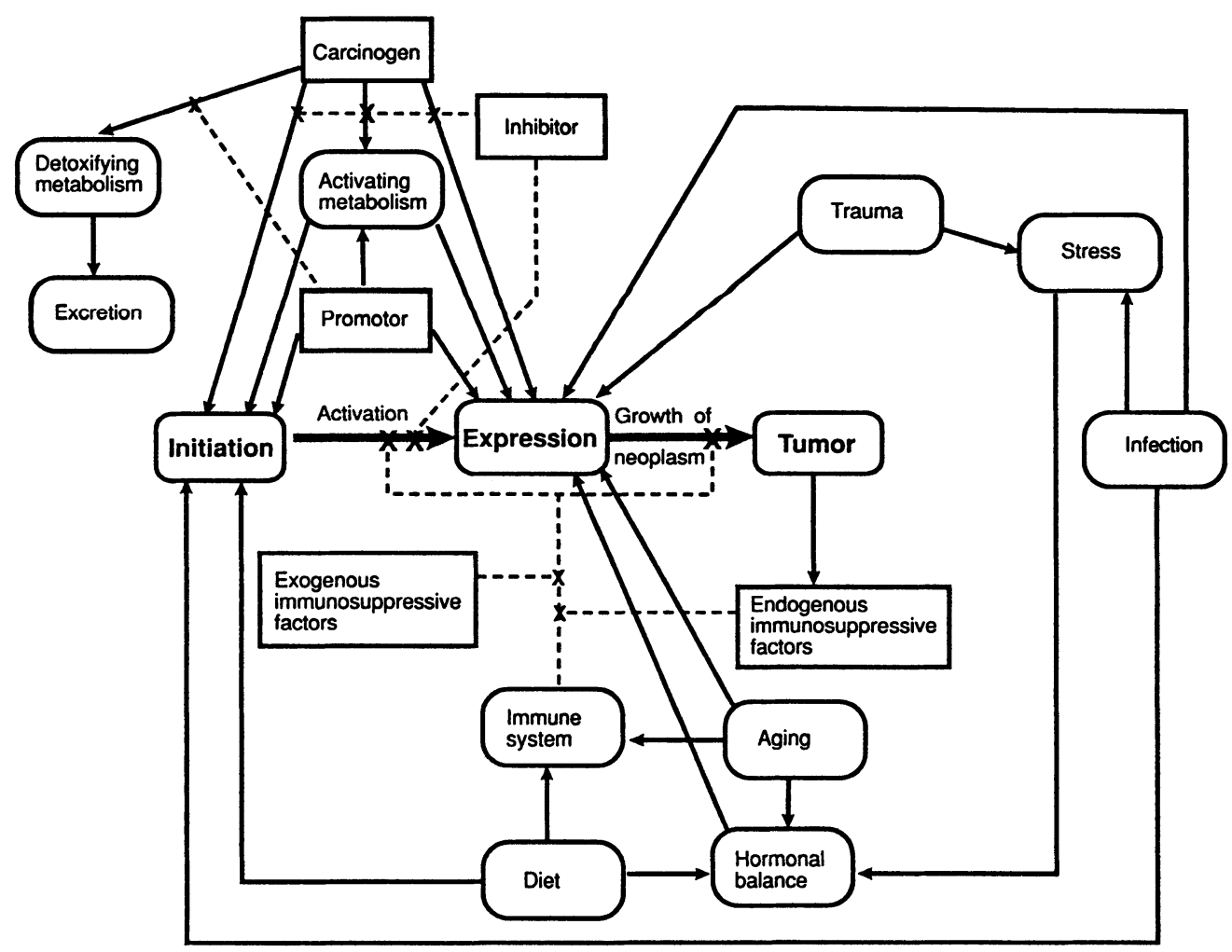

FIGURE 12.3 Factors influencing tumor induction. Rounded boxes represent physiological functions or processes while squared boxes denote a chemical or physiological factor. Solid lines show direct influence or promotion of a function, and x's at the end of dashed lines indicate antagonistic or blocking effects on a function. After (19). 
errations, or cytogenetics tests and specific locus mutations that measure gene mutation rates, are not in widespread use and will not be discussed here. For more information, review articles can be of interest (130). The two assays most commonly employed will be discussed here.

Animal bioassays usually involve the use of small rodents. The animals are exposed to the test substance by feeding, skin absorption, induction into the respiratory tract, subcutaneous injection, or by whatever method is necessary to duplicate the expected human route of entry. After the testing period is completed, the animals are sacrificed and autopsied; all tissues are surveyed for histopathological abnormality. The pathologist determines from this examination whether a neoplastic change has occurred. If a tumor is found, its histological type is determined and the degree of any malignancy is estimated. This information is quantitated and compiled into a carcinogenicity index for the test substance. The following basic principles have become generally accepted in designing and analyzing animal bioassay experiments:

- Results of test. A positive result is considered more definitive than a negative result. If there is no evidence that a test substance produces a tumor under the designed test conditions, it does not mean that under other conditions, such as using different animal species, routes of administration, or dietary conditions, further testing will not produce positive results.

- Exhaustive testing. Considering the above principle, no substance should be determined to be without carcinogenic properties in humans unless it has been tested in various mammalian species, by several routes of exposure, and for substantially the entire life span (but at least one-half of the life span) of each species. A number of species is used for carcinogenicity testing because the intermediary metabolism of a compound varies significantly between species as well as between tissues of the same species (481). Toxicologists look for variations in susceptibility to carcinogenicity of a substance as a result of sex, dietary conditions, and age. Because the incidence of human cancer increases with age, short-lived test species are usually used.

- Length of test. The universally accepted minimum length of time for a chemical carcinogenesis testing experiment is one year; ideally it should take two years, unless a statistically significant result becomes evident earlier.

- Extrapolation. In biological science, a 0.1 percent difference between control groups and test animals would not be regarded as statistically significant. However, this could translate to 100 cancer deaths per 100,000 population, a decided public health hazard.

- Size of group. It is important to choose a large enough test group to ensure that statistically significant test data is generated. But for some compounds which may be only weakly carcinogenic, even a large group might not detect cancer activity. For example, if a group of 200 animals, which is considered to be a good-sized test group, were to be challenged with a carcinogen that at a given dose level induces tumors at a rate of 0.2 percent, none of the animals will probably produce a tumor. Moreover, even if one animal developed a tumor, this result would be considered statistically meaningless. Thus, to try to detect chemicals that produce a low incidence of cancer in relatively small groups of test animals, researchers administer the chemical at relatively high dose levels (481).

\section{In vitro assays}

Because of the high expense and length of time characteristic of animal bioassays, methods have been sought to obtain screening data quickly and inexpensively. These in vitro tests are (or should be) used only to determine which substances should be submitted to the in vivo assay, since the extrapolation of the data obtained from in vitro tests to humans is orders of magnitude more difficult than the data from animal studies. As mentioned earlier, two basic types of in vitro studies are most commonly used. 
- Cell transformation. This technique is based on the fact that transformation of mammalian cells by carcinogenic chemicals can be observed in tissue culture. In Section 11.5 we discussed cell transformation resulting from oncogenic virus infection; similar effects can be observed as a result of chemical transformation. Instead of the orderly growth normally seen in tissue cultures of mammalian cells, cultures of transformed cells spread in a disordered fashion and tend to pile up on top of each other. If the transformed cells are injected into a test animal of the same species and strain that the cells were originally derived from, a malignant tumor will almost invariably result.

- Mutagenicity tests. In these tests, the assumption is made that the carcinogenicity of a substance depends upon its mutagenic potential, which is the ability of a substance to damage the cell's heredity material. Therefore, it is reasoned, compounds that are mutagenic are also likely to be carcinogenic. Mutagenicity testing can utilize various systems, such as yeast, plant cells, tissue culture cells, and fruit flies. One very effective test, the Ames test, utilizes a bacterial system, Salmonella typhimurium, together with mammalian liver microsomes for enzymatic activation of the test substance (14). The Ames test has established that over 90 percent of the chemical carcinogens tested out of more than 3,000 carcinogenic and noncarcinogenic compounds were also mutagens. The Ames test is therefore an outstanding screening tool to detect mutagenicity; these chemicals can then be removed from consideration for use in consumer products or where their use could become a hazard. Potentially economically valuable compounds, after passing the Ames test, could then be submitted to in vivo bioassay to further establish any lack of hazard.

\section{Extrapolation of test results to humans}

After possible carcinogens have been tested, the data must be converted into a meaningful form in terms of the risk to humans. Direct extrapolation of results from in vitro screening tests are generally not quantitatively useful in establishing the potential for carcinogenic hazard, but better extrapolations can be made from animal test results. Extrapolations can be made by using, for example, factors of increase of tumor incidence over the spontaneous background, or by using data from mutagenesis by radiation. As experience increases in interpreting these systems and evaluating more data from newly tested carcinogens, our confidence in our ability to extrapolate carcinogenesis test data will increase.

\section{Classification of chemical carcinogens}

Chemicals that have carcinogenic potential have been identified from all physical states and chemical types. Carcinogens can be solids, liquids, or gases; they can be organic or inorganic chemicals; they can be simple structures or highly complex in structure. There is no single rule that would allow the prediction of carcinogenicity of a particular newly synthesized chemical. However, the major chemical groups of carcinogens include the polycyclic aromatic hydrocarbons, aromatic amines, azo derivatives, nitroso compounds, alkylating agents (which include the aziridines, sulfonic acid derivatives, and some aliphatic compounds), many naturally occurring compounds (such as aflatoxins), and some inorganic chemicals (asbestos, arsenic, salts of beryllium and cadmium, and the pure metals or salts of nickel, chromium, cobalt, and lead). Table 12.6 lists some of the known chemical carcinogens and also some of the thousands of suspected carcinogens identified to date.

Chemical carcinogens, like other toxic chemicals, exhibit an organ specificity that causes the primary damage from the substance to be expressed in that particular organ. For example, chronic exposure to benzene causes leukemia, a cancer of the hematopoietic (blood and blood-forming) system, while benzidine is a potent inducer of urinary bladder cancer. Table 12.7 lists some chemical carcinogens or suspected carcinogens and the affected critical, or target, organ in humans. 
TABLE 12.7 Carcinogens or suspected carcinogens and their target organs

\begin{tabular}{|c|c|}
\hline Chemical & Target organ \\
\hline \multicolumn{2}{|l|}{ Acrylonitrile } \\
\hline Dioxins & Colon \\
\hline 3-Methyl-4-aminobiphenyl & \\
\hline Benzene & \\
\hline Melphalan & Hematopoetic system \\
\hline Phenacetin & Kidney \\
\hline \multicolumn{2}{|l|}{ Aflatoxins } \\
\hline Carbon tetrachloride & Liver \\
\hline \multicolumn{2}{|l|}{ Safrole } \\
\hline \multicolumn{2}{|l|}{ Vinyl chloride } \\
\hline \multicolumn{2}{|l|}{ Asbestos } \\
\hline \multicolumn{2}{|l|}{ bis(2-Chloroethyl) sulfide } \\
\hline \multicolumn{2}{|l|}{ bis(Chloromethyl) ether } \\
\hline \multicolumn{2}{|l|}{ Chloromethyl methyl ether } \\
\hline \multicolumn{2}{|l|}{ Chromium } \\
\hline \multicolumn{2}{|l|}{ Nickel } \\
\hline \multicolumn{2}{|l|}{ Nitrogen mustard } \\
\hline Cadmium & Prostate \\
\hline \multicolumn{2}{|l|}{ Arsenic } \\
\hline Benzo[a]pyrene & Skin \\
\hline \multicolumn{2}{|l|}{ Polychlorinated biphenyls } \\
\hline \multicolumn{2}{|l|}{ 4-Aminobiphenyl } \\
\hline \multicolumn{2}{|l|}{ Benzidine } \\
\hline $\begin{array}{l}\mathrm{N}, \mathrm{N}-\text { bis (2-Chloroethyl)-2- } \\
\text { naphthylamine }\end{array}$ & Urinary bladder \\
\hline Cyclophosphamide & \\
\hline 2-Naphthylamine & \\
\hline
\end{tabular}

Source: OSHA.

Like many other toxic chemicals, chemical carcinogens can undergo metabolic transformations that can either increase or reduce the carcinogenic activity of the compound. Biotransformation was discussed in Section 12.4 as it applies to toxic compounds, and this mechanism is not only active but seems to be especially important for many carcinogens $(14,207)$. Substances that need to undergo biotransformation in order to become active carcinogens are known as proximate carcinogens, while those which are active in their own right are called primary carcinogens. Of course, compounds can be detoxified by metabolic enzyme systems but a competitive balance between the activation and the detoxification biochemical pathways will actually prevail; the ability of the substance to produce tumors will depend upon the actual biochemical balance achieved.

\subsection{Hazards of Mutagens and Teratogens}

Until now, we have been discussing toxic chemicals and chemical carcinogens in terms of the health effects on those individuals exposed to direct contact with the substance, that is, the present generation. Mutagenic and teratogenic agents, or "reproductive toxins," have the special distinction of possessing the potential to cause irreversible damage or death to future generations. While other toxic chemicals act by damaging metabolic functions or organs and tissues in the exposed individual, mutagenic agents can produce mutations and genetically induced congenital malformations, metabolic errors, or fetal death. Teratogenic agents, while not affecting the germ plasm, can damage the developing embryo or fetus, resulting in congenital problems or fetal death.

A wide range of adverse reproductive outcomes is possible as a result of exposure to reproductive toxins. Before conception, parental exposure may result in infertility or reduced fertility, unsuccessful fertilization or implantation, or fetal abnormality. Maternal exposure after conception may result in fetal death or congenital abnormalities. Examples of adverse outcomes of pregnancy can include spontaneous abortion, birth defects, perinatal death, altered sex ratio, low birth weight, developmental or behavioral disabilities, and exposure to potential carcinogens via the transplacental route (Table 12.8) (441).

\section{Mutagens}

Earlier in this chapter we discussed assay systems for carcinogenicity. Many of these assay systems, such as the Ames test, are based upon the premise that a carcinogen is also likely to be a mutagen, and cause damage to the genetic material of the host. Various chemicals can be tested for mutagenic activity by means of these tests, and the use of metabolic enyzme activation provided by mammalian liver microsomes allows the in vitro tests to duplicate some of the major in vivo metabolic transformations these substances undergo. Other as- 
TABLE 12.8 Placental response to teratogens

\begin{tabular}{ll}
\hline Teratogen & Effect on placenta \\
\hline $\begin{array}{l}\text { Carbon monoxide } \\
\text { Heavy metals: } \\
\text { Lead, cadmium }\end{array}$ & $\begin{array}{c}\text { Inhibits oxygen exchange } \\
\text { Transits placenta, suppresses } \\
\text { fetal enzyme activity } \\
\text { Transits placenta, binds to } \\
\text { protein and nucleic acids, } \\
\text { interferes with cell division }\end{array}$ \\
$\begin{array}{c}\text { Metabolites of } \\
\text { cigarette smoke }\end{array}$ & $\begin{array}{c}\text { interferes with normal } \\
\text { intacental function }\end{array}$ \\
Organohalides & $\begin{array}{c}\text { Transits placenta } \\
\text { Organophosphates }\end{array}$ \\
$\begin{array}{c}\text { Transits placenta, reduces } \\
\text { maternal plasma enzyme }\end{array}$ \\
\end{tabular}

Adapted from (208).

say systems look for chromosomal aberrations in test animals or in humans exposed to mutagenic compounds. Many chemical compounds have been shown to be mutagenic in the Ames test (286), and some cytogenetic studies of laboratory personnel working in chemical laboratories reported detecting a higher number of chromosomal abnormalities compared with control groups (158, 257). Also, since both parents contribute to the child's genetic complement, exposure of either parent to mutagens can affect the offspring (279).

\section{Teratogens}

Many studies have shown that numerous congenital malformations are caused by chemicals to which women were exposed during pregnancy. These substances include environmental agents, occupational exposures, and even pharmaceuticals, such as thalidomide (212, 296, 299, 439). Table 12.9 lists some teratogens, their effect, and the animals in which the effect has been shown. Teratogens may or may not have the capability of producing overt toxic effects in the individual exposed to the substance. What distinguishes a teratogen from other toxic substances is its ability to produce structural damage or interfere with the metabolism of the developing fetus, usu- ally at an early stage in its development. Teratogenesis can be caused by either toxic effects in the mother interfering with transplacental exchange of nutrients and metabolites, or the substance itself can cross the placenta producing direct injury in the developing fetus (see Table 12.8). It has also been suggested that the male can contribute to teratogenesis if substances absorbed into his body are excreted into the semen; these substances could then be absorbed through the vaginal mucosa during intercourse and affect a developing fetus or embryo (93).

The chemicals that can exert a teratogenic influence are very diverse, and it is very difficult to predict whether a newly synthesized chemical is a teratogen. In addition, teratogenic testing is more difficult to perform than ordinary toxicity testing, and most of the available information comes from accidental human exposures and anecdotal information which is, unfortunately, frequently incomplete. Furthermore, extrapolation of animal data to humans is difficult and imprecise because of differences in reproductive physiology and metabolism between species. Note that Table 12.9 shows that some pharmaceuticals are teratogens and that exposure to therapeutic doses of these chemicals can result in substantial fetal damage. Obviously, a chronic occupational dose of a teratogen can have similar effects and be far more difficult to detect, especially if an exposure to multiple agents that interact in a synergistic fashion occurs.

\subsection{Flammable and Combustible Chemicals}

The primary risk of utilizing flammable substances is the specific risk of fire, which is, of course, a severe threat to both property and personnel. In addition, many flammable chemicals do in fact have associated health risks that are independent of their flammable properties: for example, many organic solvents are quite toxic, while some are also carcinogens, mutagens, or teratogens as well. However, since the fire hazard is usually the 
TABLE 12.9 Effects of teratogenic substances in humans and animals

\begin{tabular}{|c|c|c|}
\hline Teratogen & Teratogenic effect & Experimental confirmation \\
\hline Aminopterin' & Abortions $^{2}$, skeletal and CNS abnormalities & $\begin{array}{l}\text { Mouse, rat, sheep, } \\
\text { macaque }\end{array}$ \\
\hline Anesthetic gases ${ }^{3}$ & $\begin{array}{l}\text { Spontaneous abortion, decreased birth weight, } \\
\text { stillbirth, increased frequency of cardiovascular } \\
\text { birth defects }\end{array}$ & Rat \\
\hline Carbon disulfide ${ }^{4}$ & Spontaneous abortion, premature births & Mouse, rat \\
\hline Cigarette smoke constituents ${ }^{5}$ & $\begin{array}{l}\text { Spontaneous abortion, fetal growth retardation, } \\
\text { abrupto placentae, placentia previa, increased } \\
\text { neonatal deaths, sudden infant death syndrome, } \\
\text { lag in cognitive development }{ }^{6}\end{array}$ & Mouse, rat, rabbit, sheep \\
\hline Diethylstilbestrol (DES) ${ }^{1}$ & $\begin{array}{l}\text { Spontaneous abortion, trans-placental } \\
\text { carcinogenesis, increased perinatal death rates, } \\
\text { epididymal cysts }{ }^{7} \text {, hypertrophic testes }{ }^{7}\end{array}$ & $\begin{array}{l}\text { Mouse, rat, hamster, } \\
\text { rabbit, rhesus monkey }\end{array}$ \\
\hline Diphenylhydantoin (DPH) ${ }^{1}$ & $\begin{array}{l}\text { Spontaneous abortion, craniofacial abnormalities, } \\
\text { fetal growth retardation, mental retardation }\end{array}$ & Mouse, monkey \\
\hline Ethyl alcohol & $\begin{array}{l}\text { Reduced birth weight, increased stillbirth rates, } \\
\text { increased congenital malformation rates }\end{array}$ & Mouse, rat, guinea pig, dog \\
\hline Hexachlorobenzene $^{8}$ & Stillbirths, increased perinatal death rates & Rat, monkey \\
\hline Lead & $\begin{array}{l}\text { Spontaneous abortion, decreased birth weight, } \\
\text { premature labor, stillbirths }\end{array}$ & $\begin{array}{l}\text { Mouse, rat, hamster, } \\
\text { rhesus monkey }\end{array}$ \\
\hline Methylmercury & Fetal Minamata disease (gross CNS injuries) & Mouse, rat, hamster, cat \\
\hline Pesticides & Spontaneous abortion, low birth weight & \\
\hline $\begin{array}{l}\text { Polychlorinated biphenyls } \\
\text { (PCB) }\end{array}$ & $\begin{array}{l}\text { Stillbirths, low birth weight, congenital } \\
\text { malformations, dark brown-stained skin }\end{array}$ & $\begin{array}{l}\text { Mouse, rat, rabbit, dog, } \\
\text { swine, rhesus monkey }\end{array}$ \\
\hline $\begin{array}{l}\text { Retinoids (vitamin A } \\
\text { congeners) } 1,9\end{array}$ & $\begin{array}{l}\text { External ear malformations, cleft palate, cardiac } \\
\text { and aortic malformations, brain malformations }\end{array}$ & $\begin{array}{l}\text { Mouse, rat, hamster, } \\
\text { primates }\end{array}$ \\
\hline $\begin{array}{l}\text { Solvents (e.g., benzene, } \\
\text { toluene) }\end{array}$ & $\begin{array}{l}\text { Spontaneous abortion, certain rare congenital } \\
\text { malformations }\end{array}$ & \\
\hline Thalidomide $^{1}$ & $\begin{array}{l}\text { Congenital limb, cardiovascular, craniofacial, } \\
\text { gastrointestinal, renal malformations }\end{array}$ & $\begin{array}{l}\text { Mouse, rat, rabbit, ferret, } \\
\text { primates }\end{array}$ \\
\hline Vinyl chloride & Spontaneous abortion, congenital malformations ${ }^{10}$ & Mouse, rat, rabbit \\
\hline Warfarin 1 & $\begin{array}{l}\text { Stillbirths, premature delivery, craniofacial and } \\
\text { limb defects }\end{array}$ & Mouse, rabbit, dog \\
\hline
\end{tabular}

'Oral drug therapy experience.

${ }^{2}$ Exposure in early (3-8 weeks) pregnancy.

${ }^{3}$ Exposure of either parent.

${ }^{4}$ Exposure of only 3 to 26 parts per million.

${ }^{5}$ Less than 20 cigarettes ( 1 pack) per day.

${ }^{6}$ Injury is dose dependent.

'In the male.

${ }^{8}$ Long-term exposure (50-200 mg/day for months or years).

${ }^{9}$ From (258) and (385).

${ }^{10}$ Effects in wives of exposed males as well as environmental exposures.

Adapted from (208).

most serious hazard presented by these substances in handling and storage, they will be covered separately in the chapter on fire hazards, Chapter 16.

\subsection{Explosives and Shock- Sensitive Chemicals}

Explosives are chemicals that have the potential of extremely rapid burning, that is, they are a special class of combustible chemicals. 
The range of characteristically rapid rates of combustion of explosive chemicals has resulted in the classification of explosive chemicals from the relatively slow-burning substances, such as paraffin oil, to the extremely high combustion rates typical of high explosives. A second factor to be considered in assessing whether a chemical can behave as an explosive is its state of confinement when it is ignited. An example we can use is the burning of gasoline. Five $\mathrm{ml}$ of gasoline, when poured onto the ground and ignited, will make a brief, but unspectacular, fire. However, a far smaller quantity, when injected into the cylinder of an internal combustion engine, compressed, and ignited, will produce a powerful explosion. In order to facilitate our discussion of explosives, we will define some of the terms used to express the degrees of explosiveness of a chemical substance.

- Deflagration. This is the term used to describe the combustion of a flammable vapor (the gaseous form of a compound that is normally a solid or liquid) or gas. The characteristics of this type of burning include relatively small quantities and unconfined volumes. Deflagration is really just very rapid combustion, as in the example of the gasoline on the ground above.

- Explosion. More serious in effect, explosion is characterized by conditions of confinement of the flammable substance, together with a nearly stoichiometric mixture of air and fuel. This is exemplified by the gasolinein-the-engine example above. Typical pressures achieved by explosion reactions may be two to three times normal atmospheric pressures.

- Detonation. As this term implies, this type of explosion is particularly severe, and reaction speed and pressures developed in detonations can exceed those achieved in explosions by several orders of magnitude.

\section{Chemistry of explosions}

An explosion is produced by a very rapid decomposition of a substance. The decomposition occurs so rapidly, and so much energy is produced in the reaction, that the substance heats up, further accelerating the reaction. The area immediately surrounding the reaction cannot absorb the energy being liberated, so an area of superheated substance and air begins to develop. Air at high temperatures occupies a larger volume than at lower temperatures if the pressure is unchanged. During rapid decomposition, the temperature rises too rapidly for the volume of expanding gases to keep pace. The result is that the pressure of the gases increases dramatically. This in turn keeps the decomposing substance confined, which also contributes to increasing the speed of the reaction. Therefore, the faster the reaction proceeds, the faster the pressure builds up, and the more violent the explosion. As the reaction proceeds, the pressure increase overcomes the inertia of the surrounding but unaffected matter confining the reaction and a shock wave of overpressure moves out from the reaction. This shock wave contains pressures significantly greater than ambient atmospheric pressures, and it constitutes the blast, or the destructive force, of the explosion.

How does such explosive decomposition occur? The molecular structure of all compounds is based upon "bonding" of atoms. In simple terms, in order to synthesize most bonds, especially in complex compounds, energy is required. When the bond is broken, this energy is liberated as heat. A compound may possess much energy tied up in its chemical structure. However, in order to liberate this bound energy, most compounds must have more energy supplied to them. This generally occurs during reactions with other chemicals but sometimes the application of a lot of heat energy alone is sufficient to enable the substance to achieve its activation energy threshold, after which an energy-yielding decomposition reaction can proceed with no further stimulus. Such a compound is said to be stable.

Conversely, there are some chemicals which require very little additional energy to decompose. The friction of motion of the substance's molecules caused by a shock or even a change in the ambient atmospheric pressure can be sufficient to trigger a decomposition reaction. 
These compounds are called unstable. The degree of stability of a compound is not related to its degree of explosiveness. For example, hydrazine, used for rocket fuel, is quite unstable, while TNT, a high (powerful) explosive, can be burned or shot with a bullet without exploding.

Energy is stored in chemical bonds. Therefore, we can make some predictions about the potential explosive hazard of a chemical and its stability by examining its molecular structure. The following factors are the most important:

- Oxygen content of a compound. The existence of sufficient oxygen in a compound or in a reaction mixture to oxidize all of the carbon, hydrogen, and other oxidizable elements present to carbon dioxide, water, and other products, constitutes a hazardous condition. In fact, if a compound possesses sufficient oxygen to oxidize the other elements present in the compound to their lowest state of valency, then that compound is not only reactive, but is probably also unstable. Exceptions include nitrogen-containing compounds, for which other guidelines apply.

- Reactive groups. Some compounds have components that are self-reactive and are composed of an oxidative group together with a reductive group. These are called redox compounds (hydrazine, hydroxylamine, hydroxylammonium nitrate), and are unstable.

- Water-reactive compounds. These materials react violently with water (or moist air) and undergo extremely rapid oxidation (alkali metals, anhydrous metal oxides, nonmetal halides, etc.). Some evolve hydrogen gas when they react with water, thereby increasing the hazard involved.

- Endothermic-reactive compounds. Although this type of reaction is rare, some compounds are produced endothermically, that is, heat is absorbed into the reaction product rather than liberated. However, potentially no energy would be required to decompose these compounds, and their decomposition would release energy. These compounds are potentially unstable (acetylene, silver fulminate, calcium azide).
- Pyrophoric compounds. These are compounds that react spontaneously with air, and can spontaneously ignite (very finely divided metals, metal hydrides, carbonylmetals).

- Specific molecular features. Compounds with unusually high proportions of nitrogen, $\mathrm{N}-\mathrm{N}$ bonds, $\mathrm{O}-\mathrm{O}$ bonds, and others, are generally quite reactive and some are unstable. Some compounds possessing such energetic molecular structures are listed in Table 12.10 .

- Peroxidizable compounds. These compounds, like the pyrophoric compounds, react with air, but far more slowly. The resulting peroxides formed give rise to some very serious longer-term hazards.

Peroxides form in a process called auto-oxidization, a reaction with oxygen in the air. Ultraviolet radiation, a normal component of light, provides enough energy for the reaction to occur. This is why peroxidizable compounds are packaged in dark glass or metal containers. Peroxides can induce polymerization, and the polymerization products are

TABLE 12.10 Some molecular structures of high reactivity

\begin{tabular}{ll}
\hline Structure & Compound found in \\
\hline $\mathrm{C} \equiv \mathrm{C}$ & Acetylenes, metal acetylides \\
$\mathrm{CN}_{2}$ & Diazo compounds \\
$\mathrm{C}-\mathrm{NO}$ & Nitroso compounds \\
$\mathrm{C}-\mathrm{NO}_{2}$ & Nitro compounds \\
$\mathrm{C}-\mathrm{O}-\mathrm{NO}$ & Alkyl or acyl nitrites \\
$\mathrm{C}-\mathrm{O}-\mathrm{NO}_{2}$ & Alkyl or acyl nitrates \\
$\mathrm{C}=\mathrm{N}-\mathrm{O}$ & Oximes, metal fulmanates \\
$\mathrm{N}-\mathrm{NO}$ & N-Nitroso compounds \\
$\mathrm{N}-\mathrm{NO}$ & N-Nitro compounds \\
$\mathrm{C}-\mathrm{N}=\mathrm{N}-\mathrm{C}$ & Azo compounds \\
$\mathrm{C}-\mathrm{N}=\mathrm{N}-\mathrm{N}-\mathrm{C}$ & Triazenes \\
$\mathrm{N}_{3}$ & Azides \\
$\mathrm{C}-\mathrm{N}_{2}^{+}$ & Diazonium salts \\
$\mathrm{N}=\mathrm{N}-\mathrm{NH}-\mathrm{N}$ & Tetrazoles \\
$\mathrm{N}-\mathrm{OH}$ & Hydroxylammonium salts \\
$\mathrm{N}-\mathrm{F}_{2}$ & Difluoroamino compounds \\
$\mathrm{O}-\mathrm{X}$ & Hypohalites \\
$\mathrm{O}-\mathrm{X}-\mathrm{O}$ & Halites \\
$\mathrm{C}-\mathrm{Cl}-\mathrm{O}_{3}$ & Perchloryl compounds \\
$\mathrm{N}-\mathrm{Cl}-\mathrm{O}_{3}$ & Perchlorylamide salts \\
$\mathrm{O}-\mathrm{O}$ & Peroxides \\
\hline &
\end{tabular}


particularly unstable, especially when a compound that has formed peroxides is distilled. Distillation concentrates unstable peroxides while adding energy (heat) to the substance. The peroxide can also become concentrated if the peroxide-forming compound evaporates from its storage container.

The peroxide-forming compounds can be divided into three hazard categories. 1) Some compounds form peroxides that are so hazardous that they can spontaneously decompose during storage. 2) Other compounds form peroxides that require the addition of a certain amount of energy (distillation, shock) to explosively decompose. 3) The last group has the potential of forming peroxide polymers, a highly dangerous form of peroxide, which precipitate from solution easily and are extremely heat- and shock-sensitive. Table 12.11 lists some representative compounds from each group and also gives the maximum time (after opening the container) that the compound may be "safely" stored. At the end of this time the compound should be disposed of properly.

The hazard from peroxide formation can be minimized by inhibiting oxidation through the addition of inhibitor compounds, storing the compound at low temperatures (but see below), dating the containers when received and when opened, disposing the chemical within the "safe" period listed in Table 12.11, and finally, chemically testing for the amount of peroxide formation before undertaking distillation of the compound (237).* Keeping a compound which forms peroxides cold doesn't always prevent the creation of a hazard, however, because peroxides that have been frozen, or have precipitated, or both are extraordinarily sensitive to shock as well as to

*One test: add a few crystals of tetra-n-hexylammonium iodide (CAS \#2138-24-1) to 0.5 to $1 \mathrm{ml}$ of solvent, shake, place in boiling water for one minute, and then cool in ice water. If the solvent does not turn yellow, peroxide concentration is less than $10^{-6}$ molar; a yellow color indicates the presence of peroxides (179). To remove peroxides, add some solid lumps (not powder) of calcium hydride to the solvent. Any calcium compounds that may form are insoluble in organic solvents.
TABLE 12.11 Categories of peroxidizable compounds

\begin{tabular}{|c|c|c|}
\hline Group & Chemical & $\begin{array}{l}\text { Maximum } \\
\text { storage time* }\end{array}$ \\
\hline 1 & $\begin{array}{l}\text { Divinyl acetylene } \\
\text { Isopropyl ether } \\
\text { Potassium metal } \\
\text { Sodium amide } \\
\text { Vinylidene chloride }\end{array}$ & 3 months \\
\hline 2 & $\begin{array}{l}\text { Acetyl } \\
\text { Cyclohexene } \\
\text { Diacetylene } \\
\text { Dicyclopentadiene } \\
\text { Diethyl ether } \\
\text { Dioxane } \\
\text { 1,2-Dimethoxyethane } \\
\text { Methyl acetylene } \\
\text { Methyl cyclopentane } \\
\text { Methyl isobutylketone } \\
\text { Tetrahydrofuran } \\
\text { Tetrahydronaphthalene } \\
\text { Vinyl ethers }\end{array}$ & 12 months \\
\hline 3 & $\begin{array}{l}\text { Acrylic acid } \\
\text { Acrylonitrile } \\
\text { Butadiene } \\
\text { Chloroprene } \\
\text { Chlorotrifluoroethylene } \\
\text { Methyl methacrylate } \\
\text { Styrene } \\
\text { Tetrafluoroethylene } \\
\text { Vinyl acetate } \\
\text { Vinyl chloride } \\
\text { Vinyl pyridine }\end{array}$ & 12 months \\
\hline
\end{tabular}

*Compounds should be disposed of within this time after opening the container to avoid risk of explosion.

heat. Therefore, the storage temperature must be above the freezing point of the peroxide formed by the chemical to be stored.

\section{Shock sensitivity}

Most unstable compounds, in addition to being sensitive to heat, are sensitive to shock. In this context, shock means being struck, vibrated, or agitated. If the chemical is highly unstable, just opening the container can actually produce sufficient energy at the molecular level to affect the already unstable chemical bonds. This stress can result in bond breakage and liberation of energy; sufficient 
energy can thus be released to initiate and sustain a decomposition reaction. A diverse group of chemicals are shock sensitive. Table 12.12 lists some shock-sensitive compounds.

\section{Explosiveness and flammability}

One of the criteria that is used to classify explosive substances is the rate of oxidation or burning of the material. There is very little obvious difference between the result of a very rapid, almost explosive, burning of a gallon of solvent and a true explosion of TNT of equal energy output, except, of course, in the transitory overpressures and consequent local damage of the TNT explosion. Both events would result in more or less complete local destruction, and the only differences are technical. The blast of the high explosive would probably cause extensive structural damage, while the solvent explosion would produce a large amount of heat and fire but probably less structural damage.

The difference between these processes represents the basic difference between a deflagration reaction (a very rapid combustion) and an explosion. The very rapid oxidation of a vapor should be, and is, treated more as a fire hazard than as an explosion hazard, but the dividing line between them is quite blurred. Also, solid materials, finely dispersed as a dust, can behave in the same way as solvent vapors, and the resulting explosion can be

TABLE 12.12 Shock-sensitive chemicals

\begin{tabular}{ll} 
Acetylides of heavy metals & Nitroguanidine \\
Ammonium perchlorate & Nitrourea \\
Ammonium picrate & Organic peroxides \\
Azides of heavy metals & Perchlorates of heavy \\
Dinitroethyleneurea & metals \\
Dinitroglycerine & Picramic acid \\
Dinitrophenol & Picric acid \\
Dinitrotoluene & Sodium amitol \\
Fulminates of heavy metals & Tetranitrocarbazole \\
Mercury oxalate & Trinitroanisole \\
Mercury tartrate & Trinitrobenzene \\
Nitrogen trichloride & Trinitrobenzoic acid \\
Nitroglycerine & Trinitrocresol \\
Nitroglycide & Trinitroresorcinol \\
Nitroglycol & Urea nitrate \\
\hline
\end{tabular}

quite violent. Explosions of this type have occurred in grain elevators, occasionally with fatal consequences.

The hazards of explosiveness of a liquid or a vapor can be expressed by two physical characteristics of the substance: its flash point and explosive range. These are more fully covered in Chapter 16, but brief definitions follow.

- Flash point. The flash point of a liquid substance is the temperature at which its vapor forms an ignitable mixture with air near the surface of the liquid. Because there are several different methods used to determine the flash point, the values given in various handbooks for the same substance may be inconsistent. These values will vary depending upon the degree of confinement of the vapors. Note that only heat energy is required to ignite the vapor; this heat does not necessarily have to be provided by a spark or open flame: a hot plate may suffice.

- Explosive range. The explosive range of a vapor is expressed in terms of a lower and upper limit. These are, respectively, the minimum and maximum concentration of vapor, by percent volume in air (or other atmosphere), between which the vapor can sustain oxidation upon ignition. Below the lower limit, the mixture is too "lean," and above, too "rich," to sustain combustion. Explosive ranges can be tabulated for atmospheres containing other than 21 percent oxygen, and can be expressed for other than normal $\left(20^{\circ} \mathrm{C}\right)$ temperatures.

Therefore, a liquid can be ignited and burn explosively if temperature is at or above its flash point, and a vapor can burn explosively if its concentration is within its explosive range. These factors are discussed further in Chapter 16, "Fire Hazards."

\subsection{Overview of Chemical Hazards}

The hazards presented by chemicals constitute a broad range of physical and health effects. Health effects can be acute, or cumulative and 
chronic. It is also important to realize that many chemicals exhibit effects in more than one hazard category, and many do not signal their hazard through either immediate effects or through such warning signs as odor. Appendix 2 presents an overview of the characteristics of a large number of chemicals possessing health hazards and shows the multiple hazards associated with them. In the appendix, data are also presented for flash points and explosive ranges of these chemicals, thus giving an indication of the relative explosive hazard of the substance (the lower the flash point, the greater the hazard), the shipping class, the permissible exposure levels to the substance, and the special health hazards that may result from exposure to the substance.

\subsection{Safe Storage of Chemicals}

The safe use of chemicals in the laboratory involves more than just knowing their characteristics and potential hazards. One of the major concerns in working with chemicals is safe storage, both in the laboratory and in the storeroom. Planning for the safe storage of chemicals must consider the following factors:

- Control of quantity. For certain types of chemicals the quantity, including the sizes of individual containers as well as the number of containers kept on hand, may be regulated by code.

- Accessibility of storage area. The ability of workers to have reasonable access to chemical storage areas is important, since it reduces the need to store large quantities of chemicals in the laboratory.

- Reactivity. Incompatible chemicals must not be stored together (see Table 12.2).

- Toxicity. Highly toxic chemicals and chemical carcinogens should be stored in unbreakable chemically resistant secondary containers in a well-ventilated area. Access to these substances should be controlled, and an inventory should be maintained.

- High vapor pressure. Substances having a high vapor pressure that are either toxic, flammable, or both must be stored in a ventilated area.

- Disposal of outdated chemicals. Chemicals should be dated when received, and checked each year thereafter. Those that have been kept beyond their shelf life should be discarded. Any chemical that has deteriorated, developed corroded caps, leaks, or any other problem should be discarded.

- Regulated controlled substances. A governmental agency may prescribe the requirements for proper storage of controlled substances. In the United States, the Drug Enforcement Agency provides this guidance. Laws also exist at the state level.

The choice of an area for storing chemicals is important. If chemicals are to be stored in a storage room or stockroom, the area must be properly ventilated. Once containers have been opened, they should not be returned to the stock area. If they must be, the caps of containers of flammable or toxic material should be securely taped to prevent evaporation. Maintaining reasonable access to storage rooms tends to reduce the quantities of chemicals kept in laboratories, but access should not be completely unrestricted. Chemical storerooms must not be used as preparation areas. If an accident should occur in a storeroom while chemicals are being handled, very serious consequences could result because of the large quantities of chemicals present that could become involved in the accident.

The availability of storage space is sometimes limited (see Section 14.2), and larger quantities of chemicals than are needed for daily or weekly work are frequently stored in laboratories. It is essential that quantities stored in the laboratory be kept to a minimum, and that any applicable storage regulations be followed. Local fire codes often limit the amount of flammable chemicals and the size of containers (see Section 16.3) that can be stored in laboratories.

Shelving used to store chemicals should be designed with safety in mind. Since vibrations in the building can cause objects on shelves to creep, elastic restraining cords ("shock cords") can be stretched across the shelf face, or raised 
lips can be affixed to the front shelf edges to prevent containers from falling off. Storage on laboratory benches is both inappropriate and hazardous, especially since chemicals will be exposed to fire (from Bunsen burners), sparks (from equipment), and the possibility of being jostled by nearby activity. Storage in chemical fume hoods should also be avoided (see Section 12.14).

To limit the risks from chemical hazards, only the minimum amount of toxic, flammable, unstable, or highly reactive chemicals should be stored in the laboratory. Every chemical in the laboratory should have a designated storage space to which it will be returned immediately after use. However, these spaces should not be assigned alphabetically. The order should be determined on the basis of the reactive groups of the chemicals, so that incompatible chemicals are never stored together (see Table 12.13). Do not store chemicals close to a source of heat or in direct sunlight to avoid decomposition of the substance, or worse, a fire.

Laboratory refrigerators that may be used to store chemicals or other hazardous materials must never be used to store food or beverages, and flammable substances must not be stored in refrigerators unless the unit is specifically designed for this purpose (see Chapter 16).

\section{Storage precautions for specific chemicals}

Although care is necessary in storing all chemicals, certain classes of chemicals require particular precautions. In the case of chemicals for which no special guidelines exist, storage rules should be based upon common sense and knowledge of the characteristics of the substance. However, specific storage rules apply for certain specific chemical groups: toxic substances, water-reactive chemicals, flammable liquids, and compressed gases.

- Toxic substances. Toxic chemicals should be handled with care, and only the minimum quantities needed for the work should be present in the work area. The containers should be suitably marked with appropriate labels (see Appendix 3). In storage, segregate toxic substances from acids and oxidizing

TABLE 12.13 Compatible groups for storage of chemicals

\begin{tabular}{|c|c|c|c|}
\hline & Organics & & Inorganics \\
\hline 1 & Alcohols*, amines, amides, glycols, imines, imides & 1 & Arsenic, phosphorus, sulfur \\
\hline 2 & Aldehydes*, esters, hydrocarbons & 2 & $\begin{array}{l}\text { Halides, halogens, phosphates, sulfates, sulfites, } \\
\text { thiosulfates }\end{array}$ \\
\hline 3 & Ethers*, halogenated hydrocarbons, ketones, ketenes & 3 & Amides, azides, nitrites, nitrates, ${ }^{1}$ nitric acid \\
\hline 4 & Isocyanites, epoxys & 4 & Elemental metals ${ }^{*}{ }^{2}$ metal hydrides \\
\hline 5 & Nitriles, sulfides, polysulfides, sulfoxides & 5 & Carbon, carbonates, hydroxides, oxides, silicates \\
\hline 6 & Phenols, cresols & 6 & Arsenates, cyanides \\
\hline 7 & Peroxides, azides & 7 & Carbides, nitrides, phosphides, selenides, sulfides \\
\hline \multirow[t]{3}{*}{8} & Organic acids, ${ }^{3}$ peracids, anhydrides & 8 & Borates, chromates, manganates, permanganates \\
\hline & & 9 & $\begin{array}{l}\text { Chlorates, perchlorates, chlorites, hypochlorites, } \\
\text { peroxides }\end{array}$ \\
\hline & & $\mathbf{A}$ & Acids $^{4}$ (except nitric) \\
\hline
\end{tabular}

STORAGE RECOMMENDATIONS: A chemical in any numbered group may be stored near chemicals of an adjacently numbered group. Store chemicals such that members of lower-numbered groups are shelved above those of highernumbered groups. This list is only a guide, and does not cover all types of chemicals; only the most common are included. Store inorganics separately from organics. They may be stored on adjacent shelving units, however.

*Special guidelines cover storage of flammable chemicals (see Chapter 16).

'Except ammonium nitrate, which must be isolated.

${ }^{2}$ Keep away from moisture.

${ }^{3}$ Except acetic acid and certain others, which can be stored with inorganic acids.

${ }^{4}$ Store separately in an acid storage cabinet. 
agents, and keep containers away from heat, moisture, and light. For highly toxic substances, storage in a secondary container will help to prevent a hazard should the primary container develop a leak. It is best not to return opened containers of toxic material to a storeroom. If storage of containers that have been opened cannot be avoided, seal the cap with some type of tape or sealant to reduce escape of any vapors that may form. Never store containers of toxic materials that have been opened in a room lacking local exhaust ventilation (317).

- Water-reactive chemicals. Certain chemicals, including sodium, potassium, and many metal hydrides, react with water, producing heat and flammable gases. Other chemicals may burn upon contact with water. Storage areas used to hold water-reactive chemicals should be designed to prevent accidental contact with water. For example, these areas should not be equipped with automatic water sprinkler systems. Segregate water-reactive chemicals from other combustible materials, and be certain that the area is of fire-resistant construction.

The storage of flammable liquids and compressed gases is covered by specific laws and regulations, which are dealt with in Chapters 16 and 17 , respectively.

In summary, the following general storage recommendations should be followed for all chemical storage, in both the laboratory and storeroom.

- Do not store chemicals on the floor (except for drums, which can be kept on the floor in designated areas).

- Do not store chemicals on the top shelf of a shelving unit.

- Do not store chemicals above eye level.

- Provide edge-of-shelf restraint to keep chemicals from falling off.

- Attach shelving unit to the wall. Do not use free-standing shelf units.

- Acids should be stored in dedicated acid storage cabinets. Nitric acid must be isolated from other acids.

- Store flammable chemicals in a dedicated flammables cabinet.
- Extremely toxic chemicals should be stored in a locked cabinet.

- Do not store chemicals so that they are exposed to sunlight or heat.

- Keep water-reactive chemicals away from moisture.

- Use secondary storage containers to minimize the hazard from breakage or leaks in the primary container.

- Do not store chemicals on the open bench or in fume hoods.

\subsection{Dealing with Exposure to Chemical Hazards}

It is very important to know how to deal with an accident involving a hazardous chemical that has resulted in an acute exposure to the substance. One needs to treat the accident victim so that injury is minimized while also avoiding exposure of others to the chemical. Because of the great diversity of chemical hazards, there are a number of different accident responses that may be needed to treat a victim of exposure, depending on the nature of the hazardous substance involved.

Treatment of such accidental exposures is based upon two major factors: the route of exposure to the substance and the type of chemical involved. Exposures can be grouped into the following categories:

- Ingestion

- Inhalation

- Skin exposure

- Eye exposure (a special case of skin exposure)

Of course, inhalation of toxic gases presents different hazards and health effects from those caused by inhalation of a toxic dust, which usually does not have acute effects. And a skin exposure involving a corrosive material requires a response different from treating a skin exposure to a poisonous substance. However, general first aid for these exposures can be separated into these four categories. Treating exposures to certain highly toxic substances is covered in Section 12.13. 


\section{Ingestion}

Since it is unlikely that a large amount of material will be deliberately swallowed, ingestion perhaps represents the least important exposure hazard for laboratory accidents. Usually, an offensive substance accidentally taken into the mouth will be almost reflexively spat out before ingestion occurs. If, however, the material is swallowed, or if it is corrosive, first aid procedures will be necessary.

Corrosive burns in the mouth should be washed repeatedly with water. If corrosive materials are ingested, do not try to neutralize the chemical because the heat generated by the chemical reaction will cause substantial additional injury. The victim should be given substantial quantities of water or milk to drink to dilute the chemical, and immediately be transported to a hospital. Do not try to induce vomiting, since violent contractions of a weakened esophagus can cause it to rupture, resulting in great internal injury.

For other toxic materials, water or milk should be given as above, and if it is certain that the ingested substance was not a corrosive or a hydrocarbon such as a petroleum distillate, vomiting may be induced with syrup of ipecac. This latter procedure should only be approached with great care, especially if one is unfamiliar with first aid procedures. Immediate medical care is also required. For all poison ingestion, workers should be prepared to provide medical personnel with details about the substance ingested, its quantity and concentration, and treatment given.

\section{Inhalation}

In contrast to ingestion exposure hazards, the immediate health hazards of inhalation of toxic substances are very high, as the potential for rapid effects on the victim are so great. A victim of exposure to toxic gases should be immediately removed to fresh air. However, great care must be used to make sure that rescuers do not also become victims, thereby compounding the seriousness of the accident.

If the victim is unconscious and breathing has stopped, artificial respiration should be administered. (If hydrogen cyanide is the cause of the injury, do not use mouth-tomouth resuscitation, see Section 12.13.) Oxygen may be administered if available. An unconscious victim whose breathing has not stopped should be placed in a face-down position to maintain a clear airway by preventing inhalation of vomitus or foreign objects (false teeth, etc.). For a conscious casualty, maintain close observation until medical attention arrives; but in all cases, seek prompt medical assistance. Again, be prepared to provide details about the substance inhaled and the treatment given.

\section{Skin exposure}

Splashes of chemicals on the skin can be divided into two general types: corrosives and chemicals toxic upon absorption through the skin. For chemical splashes on the skin remember four things: SPEED, WATER, MORE SPEED, MORE WATER. The faster the area affected by the spill is drenched with copious quantities of water, the lesser the chance of serious injury or poisoning. All affected clothing should be removed at once. Rings and watchbands trap contaminants, so jewelry must be removed also. Soap is very effective at removing chemicals which are water-insoluble, and should be used gently while flushing the skin continues.

Continuous drenching of the skin should be performed for at least ten minutes, or until there is no evidence of remaining chemicals on the skin, whichever is longer. For spills involving large portions of the body, for phenol or hydrofluoric acid spills of any size, or where serious chemical burns have occurred, the casualty must receive extremely prompt medical attention. As before, complete details must be provided to medical personnel. Remember that the contaminated clothing removed from the casualty contains hazardous chemicals and be certain that the clothing is either completely decontaminated before being returned to the casualty, or is treated as hazardous waste. Leather (belts, shoes) frequently cannot be decontaminated and must be destroyed. 


\section{Eye exposure}

The same rules apply for treating splashes into the eyes as splashes on the skin. Speed and water are again the first aid treatment of choice. The most dangerous chemical spill into the eye in terms of rapid damage involves strong alkalis, so great care is required in treating this type of spill. A peculiarity of the eye is its tendency to immediate spasm, closing the eye firmly. This requires that the person who aids the victim carefully open the eye(s) while drenching them with a steady, soft stream of water. A powerful water stream can cause additional damage to the eye. Check for the possibility of the presence of contact lenses, which can retain the substance between the lens and the cornea and not allow the water to bathe the eye completely.

Eye splashes must be irrigated for at least 15 minutes continuously before moving the casualty. Do not stop the irrigation before this time has elapsed, unless directed to do so by medical personnel. Any person with an eye injury should be seen by a physician, preferably within the hour following the accident. All details of the accident should be furnished as before.

\subsection{Dealing with Exposure to Highly Toxic Chemicals}

Some chemicals present such a high degree of hazard that the generic first aid treatments listed in Section 12.12 are insufficient to deal with the injury. Chemical exposures involving these substances are so dangerous that an immediate response appropriate for the chemical is necessary. Treatments for exposure to cyanides, phenol, and hydrofluoric acid and hydrogen fluoride are given below.

Exposure to cyanides can be especially hazardous and requires an urgent response if gaseous hydrogen cyanide is inhaled or soluble cyanide compounds are ingested. Inhalation of dusts of cyanide compounds or skin absorption of these compounds is less hazard- ous, and requires only standard medical poisoning management or flushing of the skin with water as described above. Management of cyanide gas inhalation involves immediate removal of the casualty to fresh air, without risking exposure of the rescuer to toxic gases. Because cyanide acts extremely rapidly, speed is of prime importance, but not at the risk of the rescuer's life. If the casualty is still conscious, he should be made to lie down and remain quiet until medical attention arrives. Contaminated clothing should be removed, and the affected area flushed with copious quantities of water. The person should be kept warm. Should the victim be unconscious, he or she should be positioned mouth down to maintain a clear airway. The rescuer can hold an amyl nitrite pearl (available in cyanide poisoning treatment kits-one should be available wherever cyanide is used) beneath the victim's nose for not more than about 15 seconds per minute. If more amyl nitrite is given, it may reduce the victim's blood pressure to dangerous levels. Alternate amyl nitrite inhalation with administration of oxygen until medical assistance arrives. If the person is not breathing, commence artificial resuscitation (but do not use the mouth-to-mouth method, rather, use the compression method), and administer the amyl nitrite and oxygen when respiration commences. Immediate medical attention must be obtained.

For an accident involving ingestion of cyanides, administer one pint of 1 percent sodium thiosulfate, and then induce vomiting with soapy water or mustard water. Refer to standard first aid manuals for methods of inducing vomiting. It is urgent that all cyanide poisoning cases receive immediate medical treatment.

Phenol splashes on the skin constitute a real emergency, especially if large areas are involved. Phenol is rapidly absorbed through the skin, and can cause rapid death through respiratory collapse and kidney failure if the spill involves more than about 10 percent of the body area. Phenol splashes should be treated in the same fashion as ordinary chemical spills on the skin; all contaminated clothing must be removed and the affected area copiously 
flushed with water for at least 15 minutes. Medical treatment must be obtained with all possible speed.

Hydrofluoric acid and hydrogen fluoride are also highly hazardous. The concentrated acid inflicts burns very rapidly, and causes extensive tissue destruction, but the dilute acid is extremely dangerous also, because its effects are insidious, and may not become apparent until major damage has occurred. The immediate response to a skin exposure to the acid or gas is to flush the exposed skin with copious quantities of cool water, while removing all contaminated clothing. Continue flushing the skin for several minutes. Seek prompt medical attention even if the injury seems slight. While transporting the victim to the hospital, continue to treat the affected area by immersing it in an ice water bath or a solution of iced benzalkonium chloride. A gauze compress of ice water should be used if immersion is not practical. Be certain any clothing or leather goods are decontaminated or destroyed. A severe burn can result from contact with residual hydrofluoric acid on these items. Contact of the liquid or vapor with the eye is extremely painful and dangerous; the eyelids must be held apart and flushed with water for fifteen minutes, proceeding as described in Section 12.12.

Casualties of hydrogen fluoride vapor inhalation should be removed to a clean atmosphere and kept warm while medical attention is sought. If the chemical has been ingested, the victim should be given large quantities of water to drink as quickly as possible. Vomiting must not be induced. To attempt to alleviate the burning sensation while medical attention is being sought, the person can be given milk or two ounces of milk of magnesia to drink.

\subsection{Protective Equipment for Chemical Hazards}

The selection and use of personal protective equipment was covered in Chapter 2. The use of laboratory coats, eye protection, gloves, and other accessories is very important in reducing the chances of severe injury in the event of a spill or splash of hazardous chemicals. Exposure to fumes, vapors, and dusts of hazardous substances is more difficult to control. Supervisors of laboratories that utilize toxic substances must ensure that adequate ventilation exists in research areas and that proper use of chemical fume hoods is stressed. Control of airborne chemicals is essential for the safe operation of the laboratory. Aerosols, vapors, fumes, and dusts are best controlled by avoiding the conditions that produce them. However, sometimes the release of airborne substances will occur. The existence of adequate ventilation controls will minimize personal exposure to these hazards.

\section{Ventilation}

In these days of energy-conscious building designers and operators, adequate ventilation in laboratories is no longer assured. The actual amount of air that should be exhausted from a laboratory is directly related to the type of work to be conducted in that laboratory, and to the hours that the laboratory is in operation. Ventilation rates are generally set by local codes based upon building or room uses: ventilation rates for research laboratories usually range from 8 to 14 air changes per hour. The usual guideline is about 0.60 to 0.70 cubic meters of air per minute (20 to 25 cubic feet per minute) per occupant plus additional air to remove odors and heat generated by equipment. An important planning point in laboratory ventilation is that all air should be exhausted; that is, none of the exhaust air from the laboratory should be utilized as make-up air to be recycled back into the air supply but must be exhausted from the building in such a fashion that it will not re-enter the building air supply (nor should conditions allow it to enter other buildings' air supplies).

The overall ventilation balance in the building should be kept positive with respect to outof-doors to avoid the so-called "stuffy building syndrome" associated with a negative air balance. Negative building air pressures can cause, among other adverse conditions, suction of sewer gases into the building through 
dry traps and may allow the concentration and build-up of indoor air pollutants. Numerous other indoor air ventilation problems have been described (435). Laboratory staff should consult with facility engineering personnel to determine the laboratory's operational needs for general ventilation.

\section{Chemical fume hoods}

Chemical fume hoods are basic protective devices found in virtually every laboratory designed for research with chemicals. Almost all laboratories built during the past 50 or 60 years have included some type of fume hood. Despite this long experience with the design of these devices and their widespread availability and familiarity, to date no standards for them have been developed and universally adopted (91). During the last few years, however, increasing concern about exposure to toxic chemicals has provided a strong impetus toward establishing criteria for fume hood design and operation.

Until recently, most people assumed that vapors or other airborne particles generated in a fume hood are completely removed from the chamber. During the past few years, we have learned that this is not true: fume hood efficiency depends upon many factors, most of which are complex and interrelated. We will examine these factors and their influence on fume hood efficiency below.

Fume hoods serve four basic safety functions in the laboratory:

1. Contaminants are removed from the work station so that they do not enter the breathing zone of laboratory occupants.

2. Contaminants are transported out of the laboratory to a point where they can be released into the atmosphere safely.

3. Contaminants are diluted with sufficient air so that their concentration is decreased below a point where they can present a health hazard.

4. Flammable vapors within the chamber and work area are diluted by sufficient air so that the chance for a fire or explosion is minimal.

These safety functions, along with the types of operations to be carried out in the hood, dictate the design of the various types of hoods. There are three different types that are commonly found in laboratories today:

- Walk-in Hood. There are times when a large item of equipment or an extra-tall experimental set-up must be provided with exhaust ventilation. The walk-in or floor-mounted hood is designed for this purpose (Figure 12.4). Drainage for spills in this type of hood can be provided by a floor drain or a floor pan which can be pumped out. Utilities can be provided on the side walls, and the sash is usually divided into sections to allow ease of access and operation.

- Distillation Hood. This type of hood is intermediate in size between the standard bench hood and the walk-in hood. Its oversized chamber height allows tall column setups, but the counter, which is at a height of

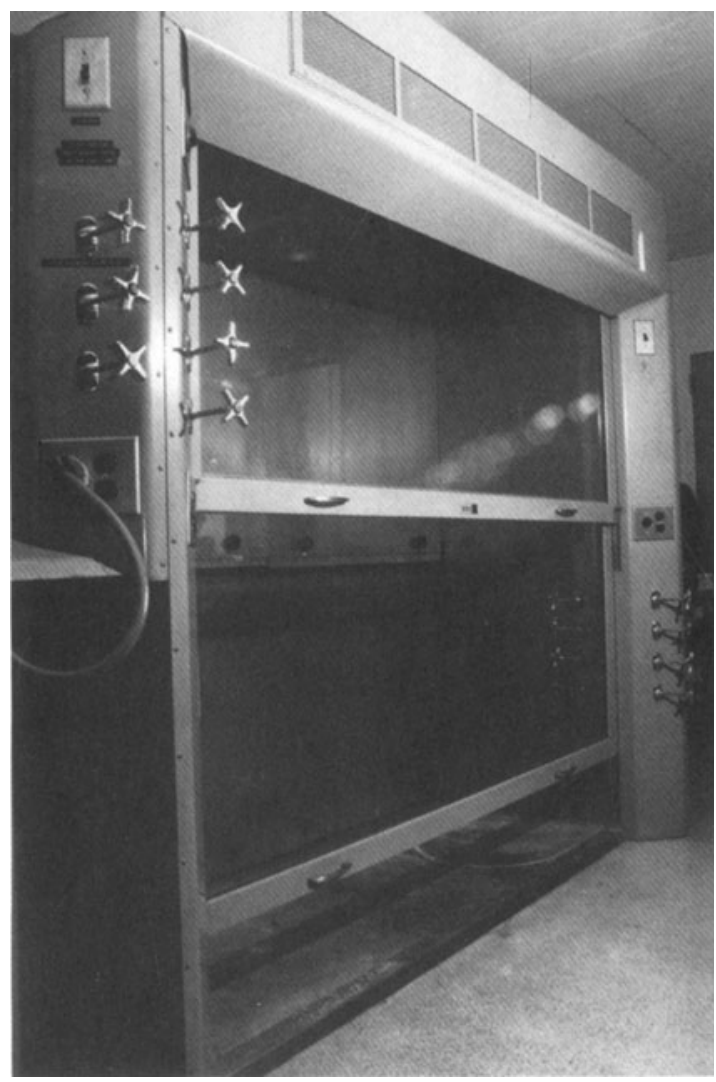

FIGURE 12.4 Walk-in fume hood. 
approximately 61 centimeters ( 24 inches), eliminates the requirement for a floor drain while facilitating the handling of tops of tall apparatus.

- Bench Hood. The most common fume hood in use, the bench hood, is best for general use for containing experiments or apparatus that produce hazardous or toxic products (Figure 12.5). The work surface is at a 91centimeter (36-inch) height, and utilities are generally provided on the side walls.

\section{Fume hood accessories}

Virtually every type of laboratory service can also be installed in the fume hood to customize it for a specific operation, or for general use. Services such as natural gas, hot and cold water, drain, steam, electricity, lighting, special compressed gas services, and distilled water can be provided.

- Service fixtures. Hoods should have remote shut-off valves for service fittings, to allow

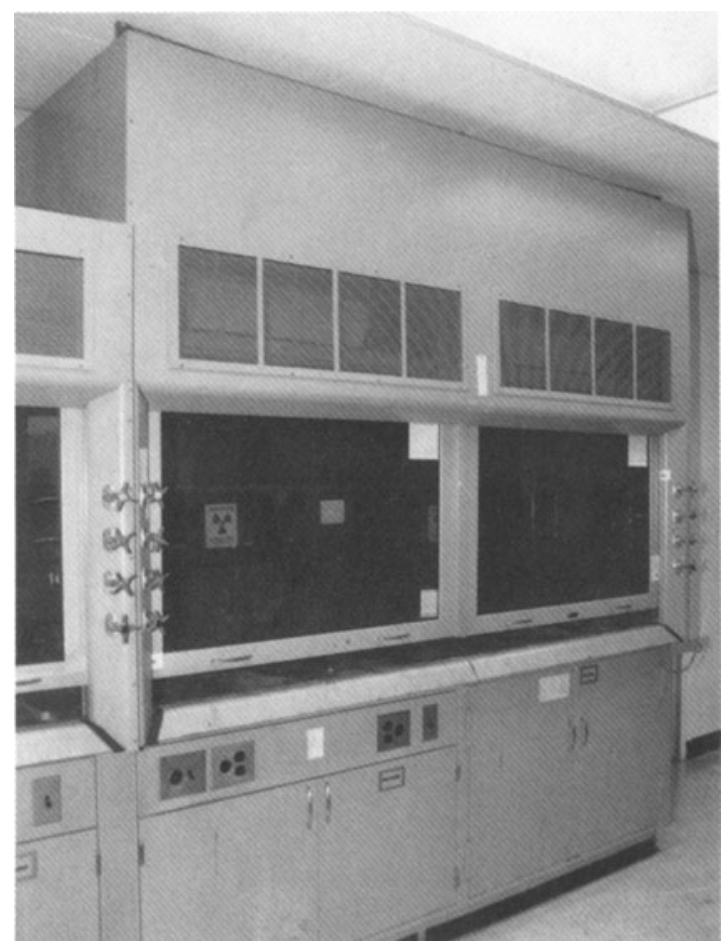

FIGURE 12.5 Bench fume hood. access to the valves during times when the unit is being operated.

- Electrical receptacles. Electrical services provided for fume hoods should be installed outside of the chamber to allow immediate access to the electrical plug, to prevent corrosion of the receptacle, and to avoid the possibility of fires caused by sparking or resistive heating of the fixture.

- Lighting. Lighting is an important feature of the fume hood. Vapor-proof fluorescent fixtures are in widespread use, and explosionproof incandescent lighting can be installed where required.

- Air flow alarms. Low air flow alarms can be included which monitor the hood's face velocity.

\section{Fume hood design}

The components of fume hoods can be divided into four categories: the supporting base cabinet, the chamber interior, the hood face (consisting of the sash and unit front), and the exhaust ductwork and fan. Each of these components is important in either the proper use of the hood or in its efficiency, or both.

Because the fume hood has become the central location for much wet chemical work, the base cabinet under most modern fume hoods has become the repository for storage of chemicals. Some hoods have even been equipped with an oven (!) in the base cabinet. Should your fume hood be so equipped, it is absolutely essential that either no chemical storage be allowed in the oven, or that the oven be completely disconnected.

If flammable chemicals are stored in base cabinets, in the U.S. the cabinets must comply with National Fire Protection Association (NFPA) Standards 30 and 45 for flammable chemical storage $(322,324)$. Venting, while not required, is also advisable.

Storage of corrosive chemicals in underhood cabinets requires that the cabinets have corrosion-resistant interiors, louvered doors, and venting into the chamber of the fume hood to draw corrosive vapors out of the cabinet. 
The chamber of a fume hood is where the work to be contained takes place. It consists of the following features and parts:

- Liner. The interior of the hood is covered with a heat- and chemical-resistant material. The standard material in use today is $1 / 4$ inch-thick transite board, a composite material whose main ingredient is asbestos. Other lining materials include stainless steel, epoxy laminate boards, or plastics. Choice of these materials is generally dictated by special operations in the use of the hood.

- Counter top. The counter top used in the hood is similar to the counter tops used for laboratory benches, and is available in various materials, including epoxy-impregnated composite, stone, transite, or stainless steel. Tops can be provided with flat surfaces, or with "marine edges" which form a dished surface to contain spills.

- Baffle. The back wall of the hood chamber, called the "baffle," forms a plenum for exhausting air from above the counter top and the lower area of the chamber. The hood should have adjustable slots in the back wall at the work surface level and at the top of the chamber. These slots are of crucial importance to hood performance (399) and are used to balance the airflow in the hood. They should never be blocked nor the position of the moveable slat changed.

- Accessories. Some hoods have built-in shelves, baskets, racks, or other accessories. These should be small, not project more than four to six inches out from the wall, and should not block or interfere with air movement within the chamber. Do not modify a hood to install such fixtures without checking the effect of the modification on airflow patterns and balance.

The front or face of the fume hood contains some of the most important design features in the hood. It consists of the sash or window, the front of the side walls, and counter-top airfoil.

- Sash. The sash of the fume hood can be of two types: vertical or horizontal. In the horizontal sash design, the window is split in half and moves from left to right, exposing only half of the work chamber at a time. Vertical sashes expose the entire width of the work surface. Some hoods incorporate both vertical and horizontal sash design features. The sash is made of 1/4-inch safety plate glass and the best sashes have the glass inserted directly into a solid metal frame structure. This helps hold the sash in the hood superstructure in the event of an explosion in the chamber, although the hood itself is not designed for blast containment.

- Side posts. Proper aerodynamic design characteristics are important considerations in efficient fume hood operation. For this reason, modern fume hoods are designed with angular-shaped side wall posts at the front of the hood. This allows air to enter the chamber smoothly without excessive turbulence.

- Airfoil. This is another very effective design characteristic. The airfoil is located below the sash at the front of the counter top. Air flows between the airfoil and the counter top, creating a laminar flow across the counter to the rear baffle slot, effectively sweeping the top clear of fumes.

The proper design of the exhaust ductwork and the fan are important to fume hood operation (275). Stories abound about fans operating backwards, ductwork improperly installed or improperly sized, or exhaust duct headers blocked (175). There are three major points to be made about fume hood exhaust systems: 1) locate the blower as far from the hood as possible to avoid pressurizing the ductwork, 2) ascertain that the air balance in the laboratory permits adequate fume hood exhaust velocities, and 3) maintain an appropriate fume hood face velocity for the designed research application. Figure 12.6 shows one design for fume hood exhausts. Loring and Goodman (275) treat this subject in detail.

\section{Fume hoods for special uses}

There are certain operations that require the use of more specially designed fume hoods incorporating certain features. The radioisotope hood and the perchloric acid fume hood are 


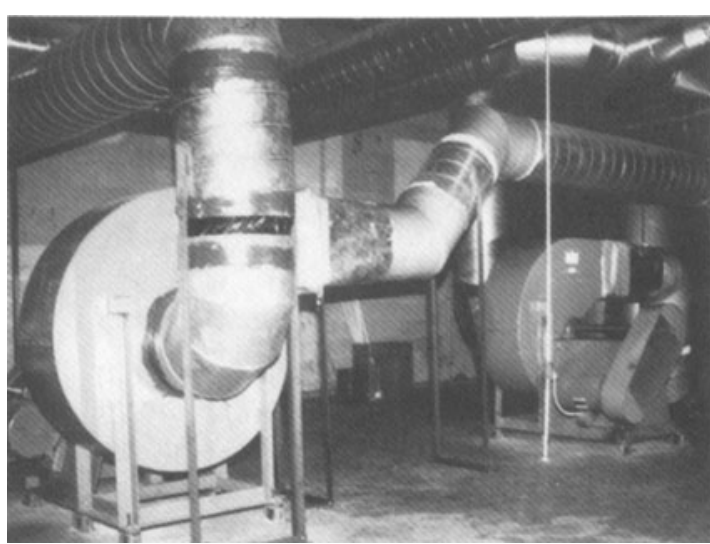

FIGURE 12.6 Fume hood exhaust blowers. Locate the exhaust fan as far from the hood as possible. Here they are located in the mechanical penthouse, only a few meters from the duct outlet to the building exterior.

examples illustrating this requirement. When perchloric acid is used in procedures where the chemical is heated, a quantity of it will vaporize. When perchloric acid recrystallizes from the vapor state, it is extremely unstable and will explode easily. Maintenance work involving the exhaust ductwork of some of these fume hoods has resulted in explosions and personal injury.

The perchloric acid hood is designed to minimize the buildup of recrystallized material, as well as the number of places available for perchloric acid condensation. The chamber of the hood is fabricated from seamless, coved type-316 stainless steel, which eliminates any joints or corners for crystals to collect. The ductwork must also be constructed from type-316 stainless steel or polyvinylchloride, and must be fabricated so that it extends vertically from the hood with no bends. Spray heads activated from the hood face are incorporated in the ductwork, permitting washing down of the duct system and air plenums of the hood. The water dissolves any residual perchloric acid crystals and the waste rinse water is drained into a trough located behind the hood baffle.

\section{Guidelines for use of the fume hood}

The fume hood is perhaps the most misused item of laboratory equipment. Fume hoods are not designed for chemical storage; the presence of many containers of various chemicals and other material that accumulates in hoods makes their operation inefficient and unsafe. Objects blocking baffle slots, operating the unit with the sash raised, inadequate airflow, and obstruction of the front airfoil are only some of the problems typically found in laboratory fume hoods. Satisfactory operation of the fume hood depends upon three factors: proper use of the chamber and work area, correct hood location, and adequate airflow capacity. These are discussed in detail below.

A fume hood must never be used for storage. Proper functioning of the hood depends upon free air passage through the chamber, and loading it with bottles, boxes, equipment, and other objects prevents free air flow $(122,348)$. Keep the area along the back wall clear, and also do not block the front airfoil. Many users inadvertently block the airfoil with benchliner material which, if improperly secured, can obstruct the air slot.

Apparatus used in the hood should be raised to allow free air passage under the item. Apparatus lacking legs, such as water baths, should be raised on blocks.

If chemicals must be stored in the hood, install narrow shelves on the side or back walls. Narrow shelves, if properly installed, will not interfere with the airflow characteristics of the hood.

The hood sash is an important safety feature in addition to its function in controlling air flow. The sash must be kept in proper operating order, and should always be kept closed whenever manual operations are not being performed. The most hazardous phase of work in the fume hood involves setting up or dismantling apparatus, or adding reagents to reaction vessels. All of these operations usually must be performed with the hood sash open, and protection is at its lowest. When the hood sash is open, the airflow velocity will probably be insufficient to contain the fumes resulting from a chemical spill, should one occur. 
Although the location of the fume hood is not under the control of the user, proper location is very important in both the efficiency and safety of the unit. The fume hood should be located out of the traffic patterns of the laboratory, away from ventilation crossdrafts, doors, and windows. Two fume hoods should not be facing one another across an aisle. Crossdrafts from ventilation and laboratory traffic can completely alter the airflow characteristics of a fume hood.

If these conditions occur in an existing installation, take steps to avoid production of crossdrafts by restricting traffic during fume hood use, baffling air ducts (but not to the point where room air balance is completely upset), closing windows or doors, or taking whatever steps may be necessary to preserve the unit's airflow characteristics.

Location of the hood is also important from a safety viewpoint. Since fume hoods are utilized for some potentially hazardous operations, they should be located near the back of the laboratory and away from exits. Should a fire or explosion occur in the hood, the laboratory layout should never require personnel to pass in front of it to reach an exit.

The question of how much air flow is needed in a fume hood has been one of the most controversial topics among fume hood design, energy conservation, and safety regulation experts. In fact, a conflict between energy conservation needs and safety requirements does exist, which can only be resolved in favor of efficient hood operation in safety terms. The inflow of air in a fume hood (the "face velocity") is measured at the plane of the sash. Face velocities ranging from 0.3 meters per second (60 linear feet per minute, Ifpm) to 0.8 meters per second ( $150 \mathrm{lfpm}$ ) have been suggested by safety personnel and hood designers. The choice of the face velocity generally depends upon the use of the hood and the anticipated hazard of the work.

The total airflow capacity of a fume hood is proportional to the cross-sectional area of the hood face and the face velocity. For a 1.5meter (5-foot) hood with a sash height opening of 70 centimeters ( 28 inches), the sash opening area is 1.05 square meters. If the face velocity is 0.5 meters per second ( $100 \mathrm{lfpm})$, then the total exhaust can be calculated from the following formula:

Total exhaust $=$ Face opening $\times$ Face velocity

In this example, the total exhaust is 32 cubic meters per minute. In order for the hood to function properly, the supply air delivered to the room when the hood is operating must equal this exhaust volume plus the general room air exhaust volume. This fact has been neglected in some installations, and has led to operational problems (175). We will discuss airflow in more detail below in the context of fume hood efficiency.

\subsection{Hood Efficiency and Energy Conservation}

During the last decade, as laboratory workers have become more aware of the hazards of toxic chemicals, regulations have been developed requiring higher fume-hood face velocities for research with carcinogens under the premise that increasing the airflow increased the safety margin-"more is better." Some groups have pressed for increasing face velocities by factors of 100 to 200 percent. However, since the costs of the energy necessary to treat the air are directly related to the face velocity, an increase of 50 percent in face velocity produces a 50 percent increase in operating costs for that hood. Because of the need for energy conservation it became imperative to develop data correlating fume-hood face velocities with their efficiency.

One research report showed that increasing the face velocity actually increased the contamination within the hood (395), presumably because of increased turbulence. Other tests culminated in the work of Caplan and Knudson, who developed a standardized procedure to measure hood efficiency (74). They defined hood efficiency by the degree of containment: the relative ability of a fume hood to contain a standard amount of airborne contaminants compared with the amount that escapes into the operator's breathing zone. The "hood in- 
dex," a ratio of these quantities, is a measure of hood efficiency. The higher the hood index value, the greater the efficiency of the fume hood.

Hood indices for various hoods operated under a wide variety of conditions have been measured using the Caplan-Knudson test. One such test had the following results (348):

- Major factors affecting hood efficiency included location of hood, location of sources of room air supply, hood configuration, and clutter and obstructions in the hood chamber.

- Hood efficiency was not affected by varying face velocities between 0.3 to 0.63 meters per second (60 to $124 \mathrm{lfpm}$ ), if all other factors were unchanged.

- At 0.5 meters per second (100 lfpm), traffic flow in front of a correctly adjusted hood had no significant impact on its performance.

- Location of the source of contaminants within the hood chamber was significant. The optimum distance from the face for hood efficiency was 12 to 15 centimeters.

There are many factors that can reduce the efficiency even of a properly adjusted fume hood. Most of these factors are under the control of the hood operator, and by recognizing their existence the operator can minimize their effects.

- If the hood is located near a doorway, the door must not be used while the hood is in use. The "pumping" action of a swinging door can draw vapors out of the face of the hood chamber, especially if the fume hood face velocity is less than 0.5 meters per second (100 lfpm).

- As mentioned above, storage of chemicals or of equipment adversely affects hood efficiency.

- In a similar vein, workload can have a negative effect. Be certain the hood can handle the work.

- Use of a hotplate or a hot water bath poses special problems, as the heat can cause undesirable convection currents. This reduces the efficiency of the hood, especially at low face velocities.
- The positioning of the sash itself is a major factor in hood efficiency. The lower the sash, the greater the efficiency since the face velocity will increase with a smaller face area.

Energy conservation and safe fume hood use are two mutually contradictory concepts. For safety reasons, fume hoods exhaust 100 percent of the air entering the hood; this is interior air that has been heated or cooled at some expense. Increasing the face velocity of a hood by 20 percent increases the energy cost by the same percentage. How, then, can these two concepts be reconciled? The work of Caplan and Knudson has shown that fume hood face velocities can be reduced in some cases without reducing hood efficiency, especially if the hood is adjusted for peak performance in all other ways.

Other methods that have been used to try to cut the loss of air that has been heated or cooled include use of the auxiliary air hood, which introduces a separate air supply at the hood face, and use of heat recovery units positioned in the exhaust system: Unfortunately, both of these methods have a high initial cost and have other drawbacks as well. Auxiliary air hoods require two duct systems and two fans, thereby increasing installation and maintenance costs. The operator may find that working at such a hood is similar to working at an open window with the wind blowing in, especially if the supplemental air is untempered. If the auxiliary air is tempered for comfort, ${ }^{*}$ however, most of the cost savings are lost, and in some instances, costs may exceed the operating cost of a standard installation (275).

Heat recovery systems are also extremely expensive, are difficult to maintain, and have potential safety problems: contaminants in the exhaust stream can infiltrate the fresh air supply through leaks or cross-contamination in the heat exchanger. However, this problem is

\footnotetext{
*The usual design involves tempering the supplemental air in the winter and using untempered air in the warmer months. This can lead to temperature gradients and fluctuations in the hood and immediately surrounding area, and if exterior humidity is high, condensation of moisture on cool surfaces.
} 
not limited to such installations; it can occur in conventional installations as well (218).

The best way of achieving energy conservation is to assure the optimum hood efficiency by retrofitting existing hoods to improve their efficiency or by purchasing new hoods with hand-operated positive energy control (HOPEC) sashes.

The HOPEC sash system is a recent innovation in hood technology. It is based upon the fact that hoods are rarely used with the sash fully open, and therefore there should be no need to set the exhaust air volume for the maximum sash opening. The HOPEC system establishes the maximum width of the opening for the sash: for example, only half of the hood face can be open without the need to unlock sash panels. If the sash is opened beyond these preset limits, as, for example, when installing equipment, an alarm is sounded. The HOPEC system can be retrofitted into existing hoods without the need for expensive ductwork, fan, and motor changes.

In summary, as workers become more aware of the potential hazards of various chemicals, and as their awareness of the importance of laboratory safety continues to rise, the need for adequate laboratory ventilation and more efficient fume hoods will become imperative. As we have seen, simply raising fume hood face velocities will certainly not make a hood safer. The need for energy conservation will certainly not disappear either. Therefore, the design, maintenance, and operation of safe laboratory ventilation systems must be the joint responsibility of the design engineer, maintenance engineer, safety officer, and laboratory hood operator. All of these individuals play important roles in the maintenance of efficient laboratory ventilation systems while minimizing the use of energy. 